\title{
Taking a crack at the dome: histopathology of a pachycephalosaurid (Dinosauria: Ornithischia) frontoparietal dome
}

\author{
Aaron D. Dyer ${ }^{a *}$, Aaron R.H. LeBlanc ${ }^{a}$, Michael R. Doschak ${ }^{b}$, Philip J. Currie ${ }^{a}$ \\ ${ }^{a}$ Department of Biological Sciences, University of Alberta, Edmonton, Alberta, Canada. \\ ${ }^{b}$ Department of Biomedical Engineering, University of Alberta, Edmonton, Alberta, Canada. \\ * Corresponding author. Email: adyer@ualberta.ca
}

C The Authors, 2021

\begin{abstract}
Recent studies have identified numerous pathologies in the cranial domes of pachycephalosaurid dinosaurs. These studies utilized CT images of domes to identify secondary woven bone and sclerosis associated with the pathologies. These features were critical for diagnosing post-traumatic osteomyelitis, which supported the head-butting behaviour hypothesis. However, conventional CT image resolution may not be sufficient to identify secondary woven bone or sclerotic bone in fossil specimens. UALVP 8504 (cf. Foraminacephale brevis), a dome possessing putative bone lesions, was thin-sectioned and micro-CT scanned. Thin sections revealed the lesions are lytic, without any secondary woven bone or sclerosis, falsifying the diagnosis of osteomyelitis. The morphology and histology of the lesions of UALVP 8504 are not diagnostic and resemble both post-traumatic and non-traumatic lesions. However, UALVP 8504 possesses shifted vascular canals (repositioning via remodeling, which maintains anatomical position throughout ontogeny) that are decoupled from growth (), and drifting osteons (secondary osteons where resorption occurs longitudinally and transversely). These demonstrate that the dome has sustained external mechanical loading, likely resulting from an impact or multiple impacts, consistent with the head-butting hypothesis. These impacts may have damaged overlying soft tissues and formed the lesions along the surface. Therefore, we suspect that the pathologies in UALVP 8504 are post-traumatic.
\end{abstract}

ARTICLE HISTORY

Received: 26-05-2020

Revised: 3-04-2021

Accepted: 10-06-2021

\section{KEYWORDS}

Drifting osteons

Histology

Pachycephalosauridae

Palaeopathology

Palaeobiology

Shifting vascular canals

\section{Introduction}

Pachycephalosaurids were small to medium sized bipedal ornithischian dinosaurs from the Late Cretaceous (Santonian-Maastrichtian) of North America (Brown \& Schlaikjer 1943; Evans et al. 2013) and Asia (Maryańska \& Osmólska 1974; Watabe et al. 2011). These dinosaurs are easily characterised by the fusion and doming of the frontals and parietals (Maryańska et al. 2004; Sullivan 2006). Dome morphology is taxonomically informative (although ontogenetically variable), and their high preservation potential (Evans et al. 2013) make isolated domes a focus in pachycephalosaurid research (Sullivan 2003; Goodwin \& Horner 2004; Sullivan 2006; Schott et al. 2009; Lehman 2010; Longrich et al. 2010; Schott et al. 2011; Evans et al. 2013; Mallon \& Evans 2014; Schott \& Evans 2016; Evans et al. 2018).

Several hypotheses have arisen to describe the function of the dome: agonistic head-butting (Galton 1971), display and species recognition (Goodwin \& Horner 2004), and thermoregulation (Rigby et al. 1987; Landry 1995). The head- 
butting hypothesis, analogous to modern bovids (Geist 1966; Galton 1971), has received the most attention and discussion. Galton (1971) argued that because the dome is comprised of dense compact bone (revised as porous compact bone (Goodwin et al. 1998) rather than porous trabecular bone, and the density of the dome increased through ontogeny (Goodwin \& Horner 2004; Schott et al. 2011; Schott \& Evans 2016)), the dome would not have been strictly used as a display feature, but was adapted to resisting the forces of intraspecific combat. Longrich et al. (2010) converged on a similar argument, elaborating on the unlikelihood of natural selection favouring such a physiologically expensive structure for the sole purpose of species recognition. Furthermore, Finite Element Analyses have demonstrated that the dome would have been capable of dispersing hypothetical combat-induced forces before reaching the brain cavity (Snively \& Cox 2008; Snively \& Theodor 2011). A posteroventrally oriented occipital condyle, and extensive development of cranial extensor musculature would have allowed the head to be held horizontally, in line with the vertebral column (Galton 1971; Maryańska \& Osmólska 1974). Tongue-in-groove articulations between zygapophyses of dorsal (Gilmore 1924) and proximal caudal vertebrae (Perle et al. 1982) may have restricted lateral flexion of the vertebral column (Gilmore 1924), strengthening the axial column during combat (Galton 1971), although the biomechanics of these tongue-in-groove articulations have not been tested.

The study of palaeopathology is a common method of inferring the behaviours, life histories, and biotic interactions of extinct animals (Bermúdes de Castro 1988; Skinner et al. 1995; Cabral et al. 2011; Hone \& Tanke 2015; García et al. 2016; Kierdorf et al. 2016; Pardo-Pérez et al. 2018; Pruden et al. 2018; Xing et al. 2018; Siviero et al. 2020). Pathological pachycephalosaurid domes have occasionally been reported, but these reports are generally anecdotal, speculative, or are considered indistinguishable from weathered domes (Maryańska 1990; Sullivan 2003; Lehman 2010; Longrich et al. 2010; Schott \& Evans 2016). More recently, lesions in some frontoparietal domes have been identified as evidence of osteomyelitis (bone infections) secondary to trauma (Peterson \& Vittore 2012; Peterson et al. 2013). These lesions were characterised as mixed (lytic - bone removed, and proliferative - bone added) pathological depressions on the dorsal surface of the dome with sclerotic and irregular surfaces, rounded margins, and peripheral pitting. Relatively coarse CT scans $(0.5 \mathrm{~mm})$ were used for histological analysis (Peterson \& Vittore 2012; Peterson et al. 2013), and suggested the floors of the lesions were comprised of thin layers of dense bone on top of low-density bands. These features were interpreted as secondary woven osseous remodeling and sclerotic bone deposition, which were considered diagnostic of osteomyelitis. Osteomyelitis can form secondary to trauma (Calhoun \& Manring 2005), and the distribution of lesions on the dome and the purported abundance of pathological specimens led Peterson et al. (2013) to support the headbutting hypothesis.

Unfortunately, normal CT scans produce images with resolutions that are often too coarse to identify histopathological features of bone resorption and secondary woven bone (beam hardening artefacts affected scans of the skull of UALVP 2; Snively \& Theodor 2011). Furthermore, similar arrangements of bone densities, like those interpreted as sclerotic and secondary woven bone, can be observed elsewhere on the scans of previously studied domes (i.e. BMR P2001.4.5; Peterson \& Vittore 2012), in regions of the dome that were not interpreted to be pathological (posterodorsal region of BMR P2001.4.5; Fig. 3B in Peterson and Vittore 2012), and may simply be artefacts of the scans. Thin-sections of pathologies morphologically similar to the pathologies described by Peterson and Vittore (2012) and Peterson et al. (2013) are herein hypothesised to have resorption lines that conform to the topography of the lesion, secondary woven bone deposited along these resorption lines, and dense, avascular sclerotic bone. The presence of these features would eliminate alternate origins (e.g., postmortem alteration) as they can only form during life. In order to assess the presence of posttraumatic osteomyelitis on pachycephalosaur domes, thin-sections were made of a suspected pathological dome to test for histopathological features of osteomyelitis. Thin-sectioning allows for direct histopathological analysis, and is thus a more effective method for diagnosing palaeopathologies (De Boer et al. 2013).

\section{Materials and methods}

Institutional Abbreviations: BMR- Burpee Museum of Natural History, Rockford, Illinois, USA; TMP- Royal Tyrrell Museum of Palaeontology, Drumheller, Alberta, Canada; UALVP- University of Alberta Laboratory of 
Vertebrate Palaeontology, Edmonton, Alberta, Canada; UATSN- University of Alberta Thinsection Number, Edmonton, Alberta, Canada.

The UALVP collection was surveyed for suitable thin-sectioning candidates. UALVP 8504 (Fig. 1) was selected, as it possesses depressions on its dorsal surface which are similar to the depressive lesions described in previous studies (Peterson \& Vittore 2012; Peterson et al. 2013). Additionally, two other domes (UALVP 49020 and UALVP 53499) were selected as comparative controls: one "healthy" dome for non-pathological bone histology and a weathered dome (Appendix S1). Specimens were photographed with a Canon
Rebel T4i, and images were manipulated in Adobe Photoshop 13.0. All selected specimens were collected from the Upper Cretaceous (Campanian) Dinosaur Park Formation, near or within Dinosaur Provincial Park, Alberta, Canada. Three pachycephalosaurids are currently recognized in the Dinosaur Park Formation: Foraminacephale brevis (Lambe 1918; Schott \& Evans 2016), Hanssuesia sternbergi (Brown \& Schlaikjer 1943; Sullivan 2003), and Stegoceras validum (Lambe 1902), although specimens of $H$. sternbergi may represent multiple species, possibly including adult $S$. validum specimens (Schott \& Evans 2016).

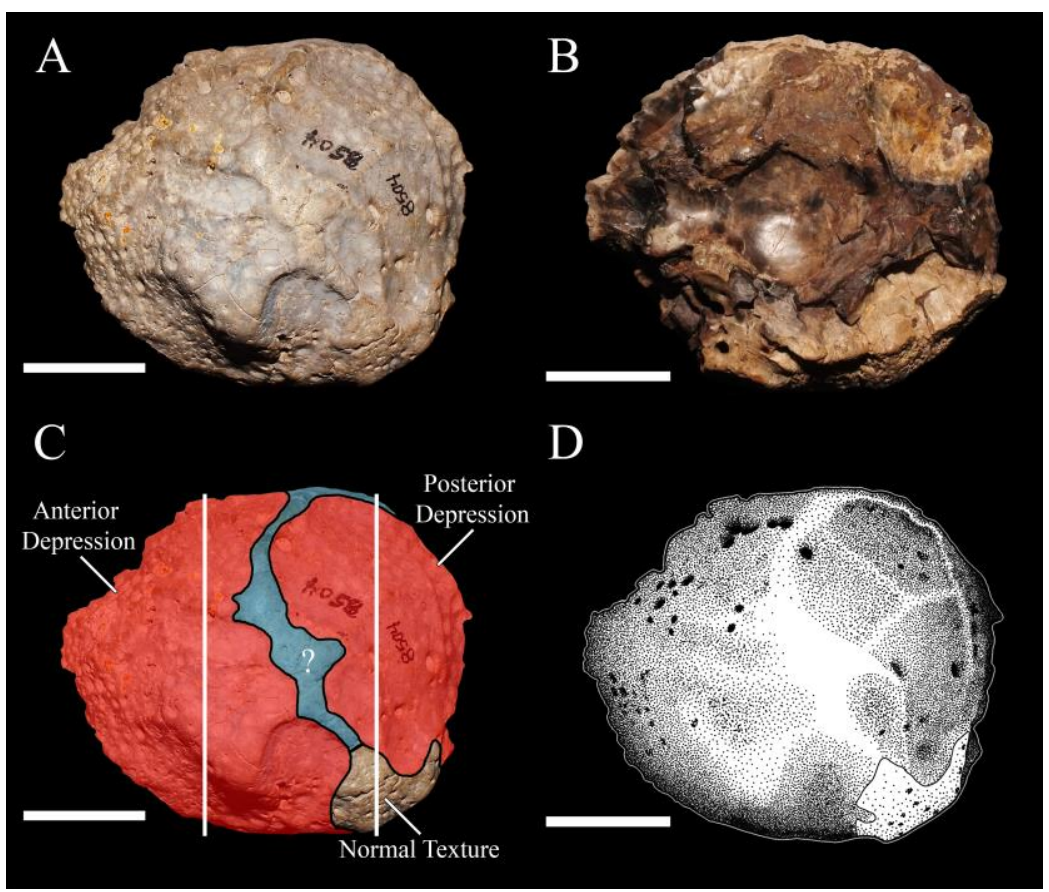

Figure 1. UALVP 8504 (cf. Foraminacephale brevis), a suspected osteomyelitic frontoparietal dome. Notes: (A) Dorsal view. (B) Ventral view. (C) Irregular depressions and non-depressed bone texture highlighted on the dorsal surface. Question mark highlights probable weathered surface. White lines denote cutting planes for thin sectioning. (D) Line drawing in dorsal view. Scale bars $=2 \mathrm{~cm}$.

UALVP 8504 was scanned using a highresolution benchtop micro-computed tomography (micro-CT) prior to sectioning. This allowed comparison and correlation of histomorphometric features between micro-CT scans and thinsections (Figs. 2, 3). UALVP 8504 was scanned using a Bruker-SkyScan 1076 micro-CT scanner (Bruker-SkyScan, Kontich, Belgium) at the Pharmaceutical Orthopaedic Research Lab (University of Alberta). Samples were scanned at $18 \mu \mathrm{m}$ resolution, with the cathode ray tube voltage / current set to $100 \mathrm{kV} / 100 \mu \mathrm{A}$, with low energy X-rays removed in all samples using a
$1.0 \mathrm{~mm}$ aluminum filter. Three scan projections were averaged per step, through the $180^{\circ}$ of rotation at $0.5^{\circ}$ step increments with exposure times of $1180 \mathrm{~ms}$. As the specimen dimensions approached the maximum that would fit into the imager gantry, offset scanning was used to acquire projection images from both left and right positions, with images being subsequently connected horizontally. The two-dimensional raw image projections were reconstructed using a modified Feldkamp back-projection algorithm, with the cross-section to image conversion values set to $0.0-0.05$ using bundled vendor software 
(NRecon, version 1.7.0.4, Skyscan NV, Belgium). Micro-CT scans are stored at the UALVP, Edmonton, Canada.

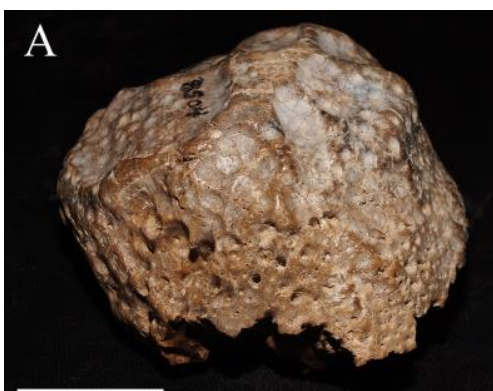

B

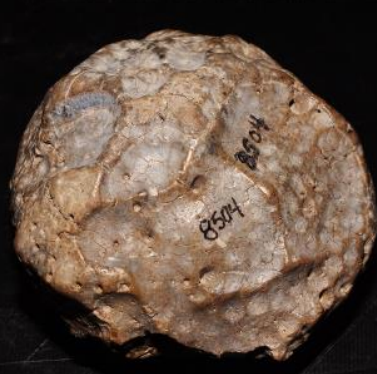

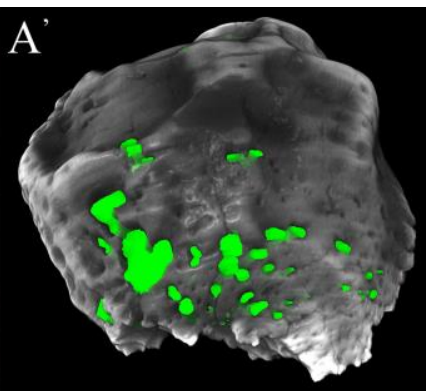

B

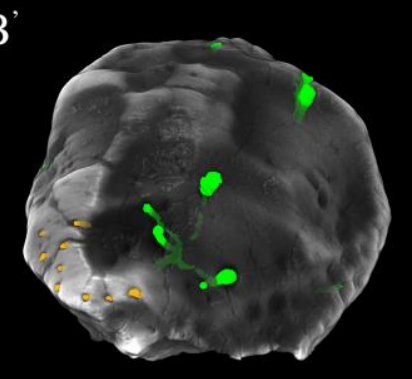

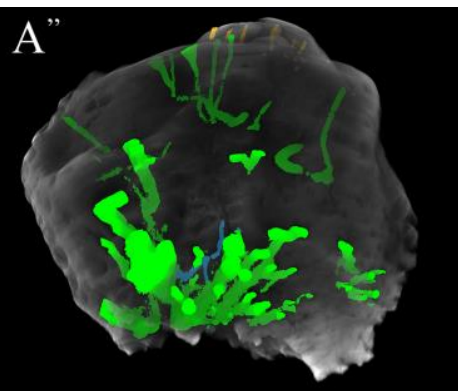

B

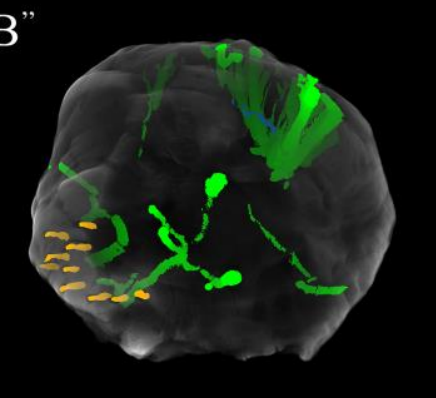

Figure 2. Cavities reconstructed from micro-CT images of UALVP 8504. Notes: Highlighted cavities include: Polykladichnus aragonensis borings (green), neurovascular foramina (orange), and shifted vascular canals (blue). (A) Photograph of the right frontal of UALVP 8504 in oblique view. (A') Opaque 3D reconstruction of UALVP 8504 in same orientation. (A') Translucent 3D reconstruction of UALVP 8504 in same orientation. (B) Photograph of UALVP 8504 in posterodorsal view. (B') Opaque 3D reconstruction of UALVP 8504 in same orientation. (B') Translucent 3D reconstruction of UALVP 8504 in same orientation. Scale bars $=2 \mathrm{~cm}$.
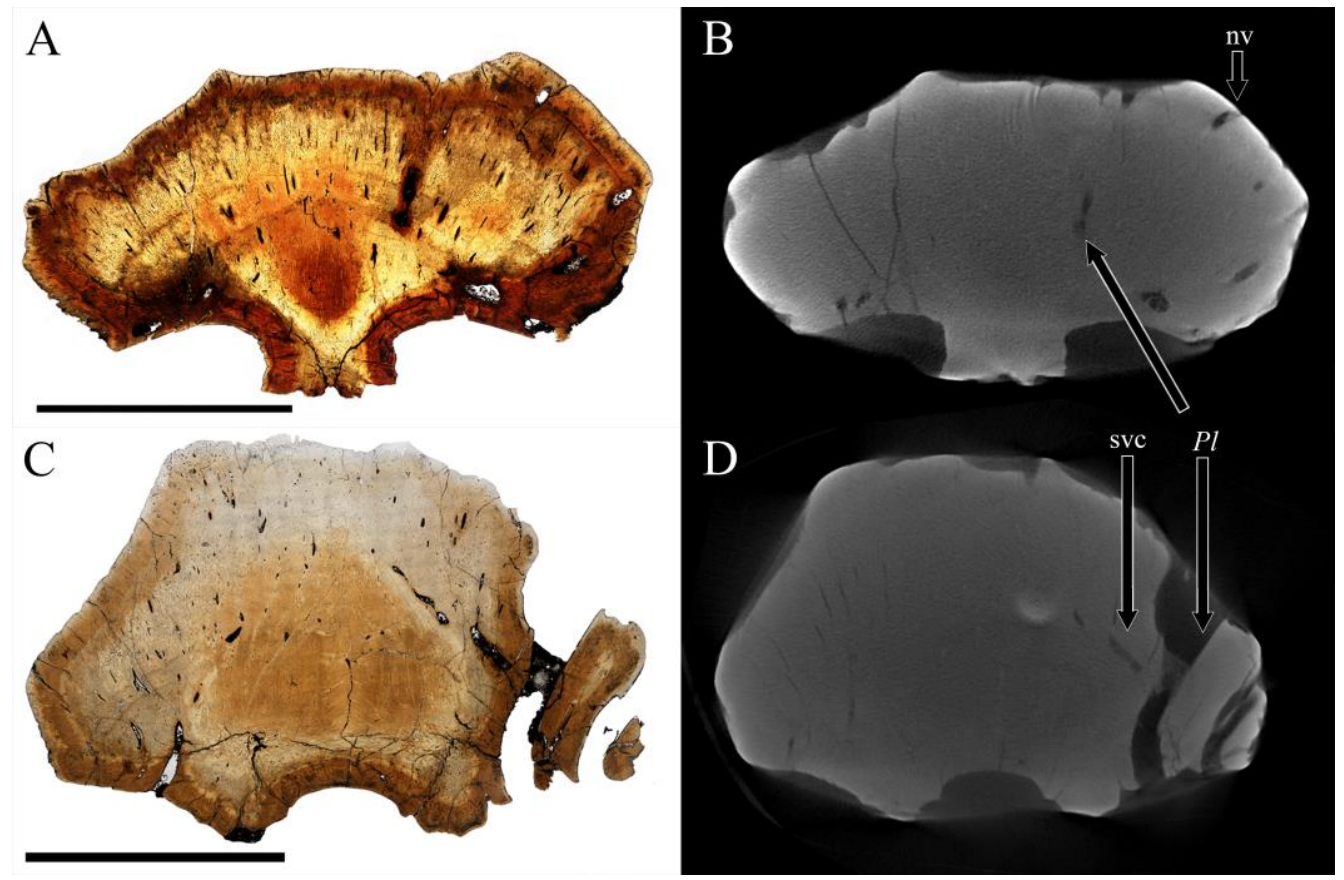

Figure 3. Comparative histology between thin-sections and micro-CT images of UALVP 8504. Notes: (A) UATSN 26 - Parietal thin section. (B) Micro-CT image of same section. (C) UATSN 28 - Frontal thin section. 
(D) Micro-CT image of same area. Scale bars $=2 \mathrm{~cm}$. Abbreviations: $P l$-Polykladichnus aragonensis; $\mathrm{nv}-$ neurovascular canal; svc - shifted vascular canals.

Specimens were embedded in Castolite AC polyester resin and placed in a vacuum to remove trapped air bubbles. Once the blocks of resin set, the specimens were cut along designated thinsectioning planes with a Buehler Isomet 1000 low speed wafer blade saw. The cut surfaces of these blocks were then ground down with 600-grit silicon carbide and then mounted with cyanoacrylate onto plexiglass slides that had also been ground with 600 -grit silicon carbide. These mounts were then cut on the Buehler Isomet 1000, $0.7 \mathrm{~mm}$ from the plexiglass slide. Slides were then ground on a Hillquist grinding machine, and further ground with 600-grit and then 1000-grit silicon carbide powder.

UALVP 8504 and UALVP 53499 were molded and cast prior to resin emersion. UALVP 49020 and UALVP 53499 were sectioned along vertical planes (Fig. S1C, D). However, due to their fragmentary nature and lack of anatomical landmarks, the exact orientation of each section is unknown. The thin-section of UALVP 49020 (UATSN 16; Fig. S2) passes along one a neurovascular foramina on the dorsal surface (Fig. S1C). The thin-section of UALVP 53499 (UATSN 36; Fig. S3) passed along the peripheral margin (Fig. S1D). UALVP 8504 was sectioned twice across coronal planes (= transverse plane in Schott et al. (2011) and Evans et al. (2013)), once across the parietals (at the contact between the sutural surfaces of for the postorbital and squamosal), and once across the frontals (cutting the sutural surface for the posterior supraorbital) (Fig. 1C). UATSN 26 and UATSN 28 were made from these parietal and frontal coronal sections respectively (Figs. 4-6). Two horizontal plane (= facial plane in Schott et al. (2011) and Evans et al. (2013)) thin-sections - UATSN 86 and UATSN 87 - were made in the area between the parietal and frontal sections (Figs. 7-9). An additional thin-section - UATSN 27 - was made along the parietal section (Fig. 10). All thin-sections were coated with mineral oil, and imaged using Nikon NIS ELEMENTS-D imaging software, and a Nikon DS-Fi3 camera mounted to a Nikon Eclipse E600 POL polarizing microscope. Further photo manipulation (e.g., stitching) was performed in Adobe Photoshop 13.0.

We follow Evans et al. (2018) by using conventional bone histology terminology when describing pachycephalosaurid frontoparietal histology, despite Horner and Goodwin's (2009) claim that the frontoparietal grew in the absence of osteoblasts and a periosteum via metaplasia (Haines \& Mohuiddin 1968). Evans et al. (2018) identified osteocyte lacunae with canaliculi in a frontoparietal dome of cf. Prenocephale (also identified in this study); the absence of canaliculi led Horner and Goodwin (2009) to hypothesize a metaplastic origin for the dome in pachycephalosaurids. A re-examination of the development (intramembranous vs metaplastic) is outside the scope of this study; additionally, Bailleul et al. (2019) argued that ground thinsections of fossilized tissues have not produced direct evidence of metaplastic ossification. Our histological observations are more accurately described using histological terms for bone rather than metaplastic tissue (see below).

Results

\section{Morphological description of UALVP 8504}

UALVP 8504 is a nearly complete frontoparietal dome (Fig. 1). The frontonasal boss, the supraorbital lobes, and the posteromedial extension of the parietals have all broken off, and are not preserved. Neither the interfrontal nor the frontoparietal sutures are visible on any surfaces, suggesting external fusion of the elements. The supratemporal fenestrae of UALVP 8504 are closed. Supratemporal fenestrae close early in the ontogeny of Foraminacephale brevis (Schott \& Evans 2016). Specimens of $S$. validum rarely have closed fenestrae, but this is attributed to individual variation, not ontogeny (Schott \& Evans 2012). The ventral surface of UALVP 8504 is well defined. The surfaces of the cerebral fossa and the temporal fossae show no abrasion (Fig. 1B). The ventral processes of the frontals and parietals (that connect with the neurocranium) are broken. These broken surfaces are blocky and irregular, unlike the rounding abrasion seen in weathered domes (Mallon \& Evans 2014). We follow Sullivan (2003) in assigning UALVP 8504 as cf. F. brevis (previously S. validum; Schott et al. 2011; Schott \& Evans 2016). The frontoparietal width (W:f/p) of UALVP 8504 was measured as $52.08 \mathrm{~mm}$, whereas Schott et al. (2011) reported the width as $62 \mathrm{~mm}$. UALVP 8504 falls within the size range for subadult to adult $F$. brevis (subadult - TMP 1985.036.0292 - W:f/p $=49.3 \mathrm{~mm}$; adult - TMP 1987.050.0029 - W:f/p $=84.1 \mathrm{~mm}$; Schott \& Evans 2016). 


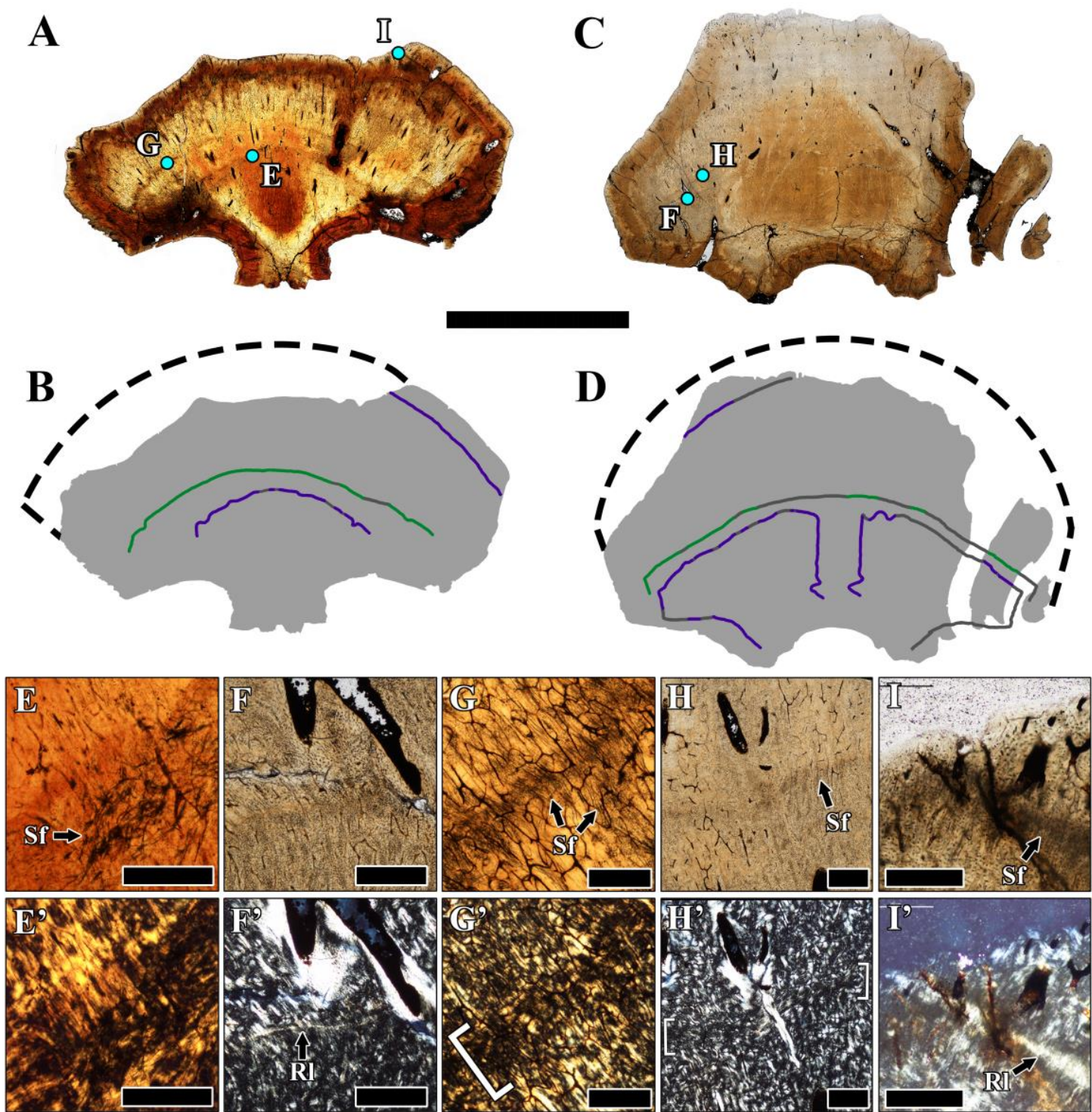

Figure 4. Growth lines in UALVP 8504. Notes: (A) UATSN 26 - Parietal thin-section. (B) Grayed outline of UATSN 26. (C) UATSN 28 - Frontal thin-section. (D) Grayed outline of UATSN 28. Blue lines indicate observed LAGs, green lines represent annuli, and grey lines indicated inferred position of growth lines (based by connecting observed lines and mirroring sides). Dashed dark lines outline bone surface prior to resorption. Scale bar $=2 \mathrm{~cm}$. (E) LAG 1 within the parietal under normal polarized light (NPL). (E') Same area under cross polarized light (CPL), the LAG is marked by an isotopic (darker, ventral) to anisotoptic (brighter, dorsal) boundary. Scale bars $=500 \mu \mathrm{m}$. Disorganized Sharpey's fibers (Sf) underlie the LAG. (F) LAG 1 within the frontals under NPL. (F') Same region under CPL. A reversal line (Rl) marks the LAG. Scale bars $=500 \mu \mathrm{m}$. (G) The annulus within the parietal under NPL. (G') Same area under CPL. A dense mat of Sharpey's fibers line the annulus. The annulus is marked by a layer of relatively isotropic bone (bracket in $\left.\mathrm{G}^{\prime}\right)$. Scale bars $=500 \mu \mathrm{m}$. $(\mathrm{H})$ The annulus within the frontals under NPL. (H') Same region under CPL. Sharpey's fibers line the annulus in H. The darker isotopic layer is marked by brackets in H'. Scale bars = $500 \mu \mathrm{m}$. (I) LAG 2 within the parietal under NPL. (I') Same region under CPL. Sharpey's fibers form a dense, blurred matt along the LAG. A reversal line marks the LAG in I'. A band of isotropic (bright) bone overlies the reversal line. Scale bars $=250 \mu \mathrm{m}$ 

The dorsal surface of UALVP 8504 is covered in large depressive surfaces (Fig. 1C), unlike the smooth convex surface expected for a subadultadult Foraminacephale brevis (Schott \& Evans 2016). Two main depressions, one positioned anteriorly and the other posteriorly, occupy most of the dorsal surface of the dome. The margins of these depressions are generally well defined; however, the anterior and lateral margins of the anterior depression, and the posterior margin of the posterior depression would have all extended past the broken edges of the dome. Vascular openings are more abundant in the area between the two major depressions (Fig. 1C), indicating limited cortical erosion in this area.

The floors of the depressions possess some shallow ridges, and are patterned by smooth dimple-like pits (Figs. 1A, D; 2B), similar to suggested osteomyelitic domes (e.g. BMR P2004.4.1, TMP1992.002.0003; Peterson et al. 2013). These pits also resemble the hypothetical resorption pits along the squamosal nodes of Stegoceras validum, where the resorption of squamosal nodes may be a late ontogenetic process (Schott \& Evans 2012). Ontogenetic resorption of squamosal ornamentation has also been hypothesised in Pachycephalosaurus (Horner \& Goodwin 2009), although no macroscopic resorption pits have been described for this taxon.

The anterior portion of the dome is slightly depressed (not to the same extent as the posterior depression), but otherwise shows little modification. Dimpled pits occur on the frontal, but they are shallower than the pits on the parietal. The dorsal surface of the dome is marked by numerous canals. Some of the smaller canals expand as they exit the dorsal surface. These flaring canals are abundant on the frontals, although a few isolated canals are present on the parietal depression. A cluster of several massive canals (diameters range from $0.65-2.07 \mathrm{~mm}$ ) is also present on the right frontal. These canals are oriented roughly perpendicular to the surface, and are concentrated at the lateral edge of the right frontal (Figs. 1A, 2A). The walls of the canals are smooth. Several of these canals branch from one another near the dorsal surface (Fig. 1). These enter the bone on the roof of the right orbit, and presumable subdivide internally because there are fewer canals on the ventral surface than on the dorsal surface (Fig. 1B).

A small area of non-depressed bone tissue remains on the left posterior portion of the parietal
(Fig. 1C). The surface is smooth and convex compared to the depressed and dimpled floors of the depressions on the frontals and parietals. This undamaged region is pierced by nearly a dozen neurovascular foramina, similar to the sectioned fragment of UALVP 49020. The presence of abundant neurovascular foramina in this region is a common feature of Foraminacephale brevis (Schott \& Evans 2016). Fewer vascular canals exit along this non-pathological surface when compared to areas between the depressions (aside from the neurovascular foramen).

\section{Micro-CT description of UALVP 8504}

Despite the high resolution $(18 \mu \mathrm{m})$, the benchtop micro-CT scans of UALVP 8504 show poor histological detail. The entire specimen appears as a single mass of uniform density (Fig. 3B, D), and does not show the typical histological zonation of pachycephalosaurid domes (Goodwin \& Horner 2004; Schott et al. 2011). These zones have been reproduced in higher powered CT scanners, albeit at lower resolution, in Stegoceras domes (Schott et al. 2011; Williamson \& Brusatte 2016). However, CT images of Foramincacephale brevis did not show normal histological zonation (Schott \& Evans 2016). The density changes previously reported and interpreted as woven and sclerotic bone (Peterson \& Vittore 2012; Peterson et al. 2013) were not reproduced in our lower energy micro-CT scans. Neurovascular foramina, flaring canals and massive canals are observable as hollow chambers, or infilled with sediment of lower density than the bone (Fig. 3B, D). The flaring canals branch and radiate from each other, and the anterior ones connect to the underlying massive canals (Fig. 2).

\section{Histological description of UALVP 8504}

The massive canals are present in micro-CT scans and thin-sections (Figs. 2, 3). The canals are tubular in shape, and generally connect the ventral surface of the frontoparietal to the dorsal surface. Unlike the large primary vascular canals, the surfaces of the structures we identify as massive canals are smooth and truncate the bone texture around them (Fig. 5F). Primary vascular canals do not truncate bone texture, and areas of bone resorption are usually lined with Howship's lacunae, which are absent from the walls of the massive canals.

Three growth lines are present throughout all three coronal thin-sections (Fig. 4). The inner (1) and outermost (2) lines are LAGs (lines of 
arrested growth), and they locally possess reversal lines (Fig. 4F, I; Huttenlocker et al. 2013), and the middle is an annulus (a darker band under cross polarized light, indicating a change in orientation of the bone collagen, Fig. 4F, H; Huttenlocker et al. 2013) without any discernible reversal lines. LAG 1 gently arcs dorsomedially in the frontals (Fig. 4D), and abruptly descends ventrally about $2 \mathrm{~mm}$ from the midline, whereas it continually arcs across the parietals (Fig. 4B). The annulus is tightly spaced dorsally to LAG 1 and follows a similar path, although it does not extend ventrally at the interfrontal suture (Fig. 4G, E). Similar to the LAG in UALVP 49020 (Fig. S2D), the growth lines of UALVP 8504 are lined with Sharpey's fibers (Fig. 4E, G-I). These are most apparent along LAG 2 and the lateral margins of LAG 1

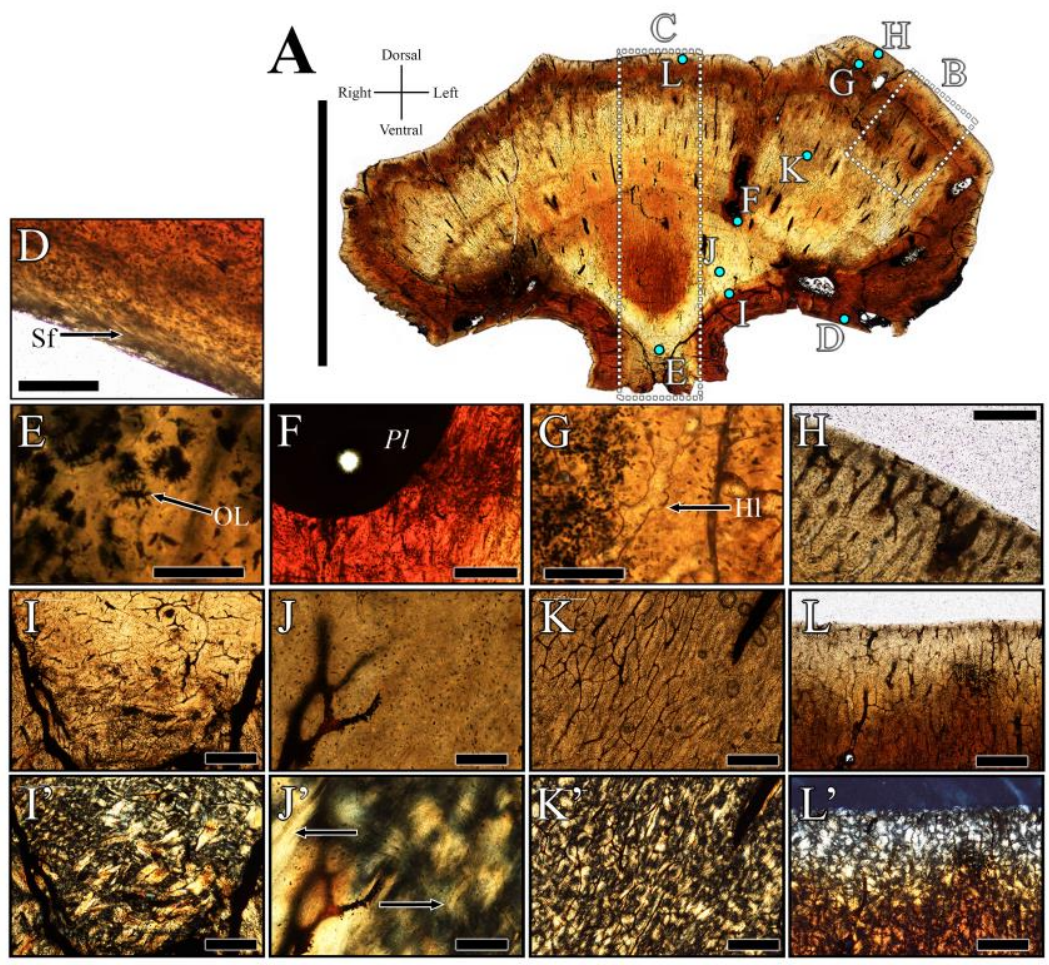

and the annulus. Sharpey's fibers associated with LAG 1 are disorganised, and frequently overlap (Fig. 4E), whereas Sharpey's fibers crosscutting LAG 2 are all perpendicular to the LAG (Fig. 4I). LAG 1 in the frontal is dorsally sinusoidal sagittally (Fig. 4D), and is reminiscent of the surficial rugosity of ontogenetically young pachycephalosaurs (Horner \& Goodwin 2009; Evans et al. 2011; Schott et al. 2011). LAG 1 and the annulus are spaced closer together in the frontals $(1.6 \mathrm{~mm})$, than in the parietal $(2.3 \mathrm{~mm})$, indicating the parietal inflated quicker than the frontals, which is consistent with the dome inflation of Foraminacephale brevis, where the parietal inflates before the frontals (Schott \& Evans 2016).

Figure 5. Parietal histology of UALVP 8504. Notes: (A) UATSN 26 - coronal plane thin-section across the parietals. Scale bar $=2 \mathrm{~cm}$. (B) Enlarged section (rotated) of the dome's cortex, distinguishing the boundary between Zones II and III. (C) Enlarged section of the dome, distinguishing the boundary between Zones I and II. Scale bar for enlarged sections $(B$ and $C)=1 \mathrm{~cm}$. (D) Sharpey's fibers (Sf) bordering the temporal fossa. Scale bar $=200 \mu \mathrm{m}$. (E) Osteocyte lacunae $(\mathrm{OL})$ displaying canaliculi. Scale bar $=50 \mu \mathrm{m}$. (F) Primary bone truncated by the boring trace Polykladichnus aragonensis (ie. massive canals). Scale bar $=250 \mu \mathrm{m} .(\mathrm{G})$ Enlarged vascular canals lined with Howship's lacunae (H1). Scale bar $=100 \mu \mathrm{m}$. (H) Cortical surface of non-depressed bone. Scale bar $=250 \mu \mathrm{m}$. (I) Secondary remodeling under normal polarized light (NPL). (I') Same area under cross polarized light $(\mathrm{CPL})$. Scale bars $=500 \mu \mathrm{m}$. (J) Poorly preserved vascular canals deep in Zone II under NPL. (J') Same area under CPL. Scale bars $=100 \mu \mathrm{m}$. (K) Radial fibrolamellar bone in Zone II under NPL. Same area under CPL. Scale bars $=500 \mu \mathrm{m}$. (L) Parietal lesion floor, truncating into Zone III, under NPL. (L') Same area under CPL. Scale bars $=500 \mu \mathrm{m}$.

Three histological zones can be observed within the coronal plane sections of UAVLP 8504, from ventral to dorsal they are: (1) reticular and horizontal primary vascular canals with some 
remodelling; (2) intact radial vascular canals; and (3) enlarged radial vascular canals with scalloped walls (Fig. 5B, C). Zones I and II are consistent with previously identified zones in other pachycephalosaurids (Goodwin and Horner 2004). Zone III is defined by novel features observed in UALVP 8504, and departs from the Zone III defined by Goodwin and Horner (2004). Osteocyte lacunae with canaliculi occur throughout all three Zones. However, the preservation of osteocytes and canaliculi is extremely variable, but are generally well defined near larger vascular canals and exterior margins.

\section{Zone I}

Zone I is comprised of a mixture of primary fibrolamellar and secondary bone. Primary vascular canals vary from reticular to horizontal, whereas secondary canals are more randomly oriented. In the parietals, secondary remodelling occurs deep within the intertemporal bridge (Fig. 5I). This remodeled region is surrounded by reticular primary vascular canals. Laterally, these grade into a longitudinal orientation, perpendicular to the medial margin of the temporal fossa (Fig. 5). Primary vascular canals bordering the temporal fossa maintain horizontal orientations as the surface of the temporal fossa curves laterally. In the coronal section across the frontals, secondary remodelling occurs parasagittally, within the respective centers of ossification of each frontal (Fig. 5E). Ventral to the area of secondary remodeling in the frontal, primary vasculature is oriented perpendicular to the endocranial fossa and orbital roof. Primary vascular canals grade to radial orientations dorsal to both the frontal and parietal remodeled centers, marking the dorsal boundary of Zone I (Fig. 5C). This gradient is drawn out longer in the parietal than the frontals.

Similar to the parietals, the remodeled centers of the frontals are surrounded by reticular primary vasculature, except medially, where primary vasculature is horizontal and longitudinal to section (lateromedially oriented) (Fig. 6B). The horizontal vascular canals gently arc dorsally towards the midline where they meet a large dorsoventrally oriented secondary osteon. This secondary osteon extends into Zone II, and marks the interfrontal suture. The lumen of this secondary osteon widens dorsally, and pinches out ventrally, indicating the osteon originated ventrally and extended dorsally as it formed. In horizontal plane sections, the frontoparietal and interfrontal sutures are completely fused internally (Fig. 7F, G). Secondary osteons (oriented dorsoventrally) sporadically line the sutures (Fig. 7F, G). 


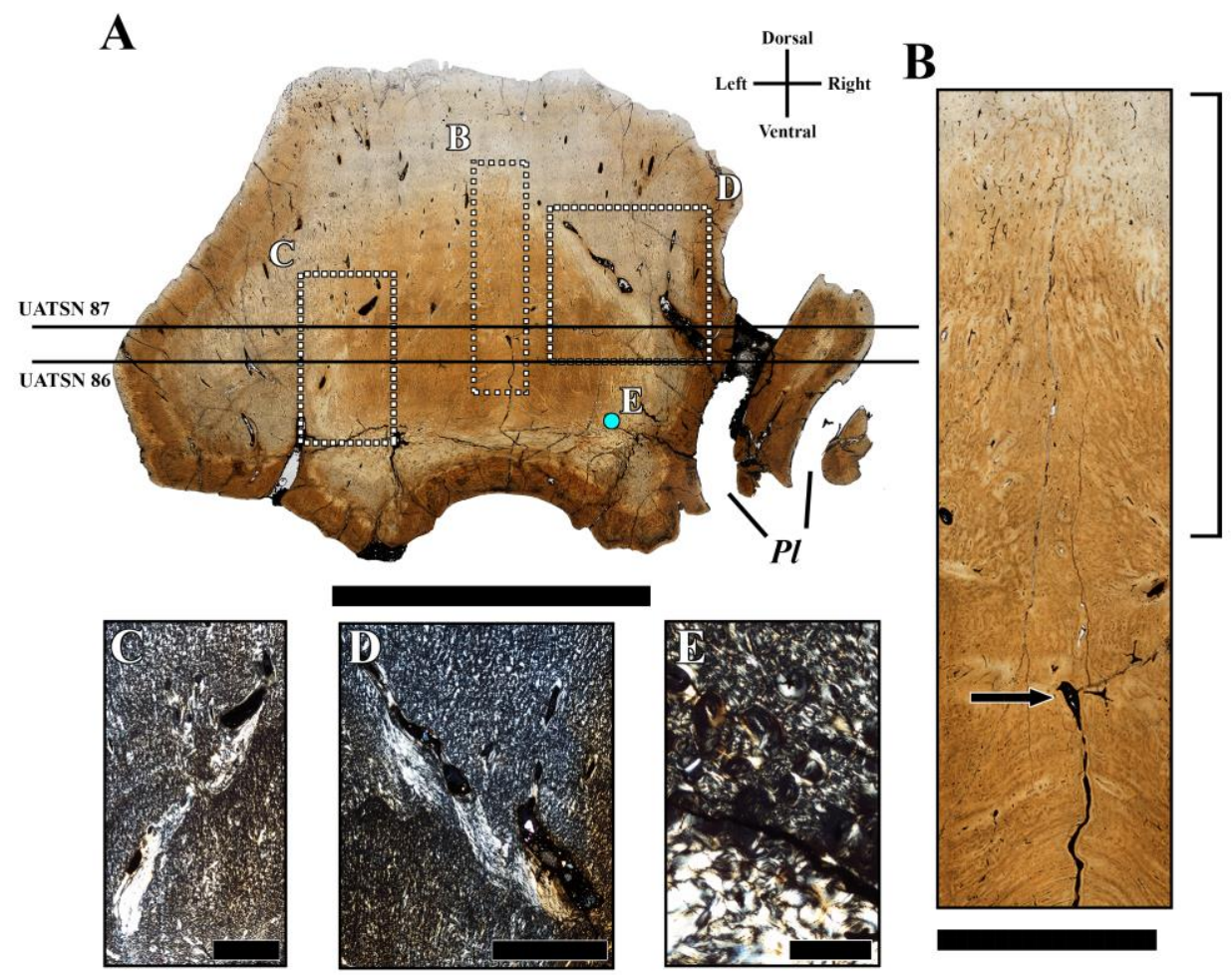

Figure 6. Frontal histology of UALVP 8504. Notes: (A) UATSN 28 - coronal plane thin-section across the frontals. Scale $b a r=2 \mathrm{~cm}$. The position of the two horizontal plane sections are denoted with black lines. Polykladichnus aragonensis bores ( $P l$ ). (B) Enlarged parasagittal section. Scale bar $=4 \mathrm{~mm}$. Arrow indicates the cutting cone of the secondary osteon along the interfrontal suture, bracket indicated region of dorsomedially oriented primary vasculature. (C) Shifted vascular canals in the left frontal under cross polarized light. Scale bar $=2 \mathrm{~mm}$. (D) Shifted vascular canals in the right frontal under cross polarized light $(\mathrm{CPL})$. Scale bar $=4 \mathrm{~mm}$. (E) Secondary remodeling deep within the right frontal under CPL. Scale bar = $500 \mu \mathrm{m}$.

Two patches of abundant Sharpey's fibers occur along the margin of each temporal fossa. These Sharpey's fibers meet the margin of the temporal fossa at an acute angle, extending dorsomedially. One patch is centered at the most medial portion of the dorsal (horizontal) margin, and the other occurs closer to the lateral extent of the fossa (Fig. 5D). These correspond with the hypothesised insertion areas for the $M$. adductor mandibulae externus medialis and M. pseudotemporalis (Sues \& Galton 1987). Sharpey's fibers are also abundant along the dorsal margin of the endocranial fossa and orbital roof of each frontal.

\section{Zone II}

Zone II begins deep within the dome with the onset of radially oriented (dorsoventrally) primary vascular canals (Fig. 5C). Zone II is mainly comprised of primary fibrolamellar bone (Fig.
$5 \mathrm{~K}$ ), with a minor contribution of primary parallel-fibered bone. Primary vascular canals are generally abundant throughout Zone II. Relatively avascular patches of primary bone occur deep within the dome, parasagittal to the midline. Despite the apparent absence of vascular canals under plane-polarized light, abundant but poorly preserved vascular canals can be observed under cross-polarized light (Fig. 5J). Primary vascular canals remain radial throughout Zone II (Fig. 5C, I; and regionally approach plexiform in UATSN 26), except along the interfrontal suture. Primary vascular canals are longitudinal and horizontally oriented (mediolaterally) between the secondary osteon along the interfrontal suture and the dorsomedial height of LAG 1 (Fig. 6B). Continuing dorsally, the immediately parasagittal primary vascular canals (within $5 \mathrm{~mm}$ of the midline) are oriented slightly dorsomedially (Fig. 6B). 

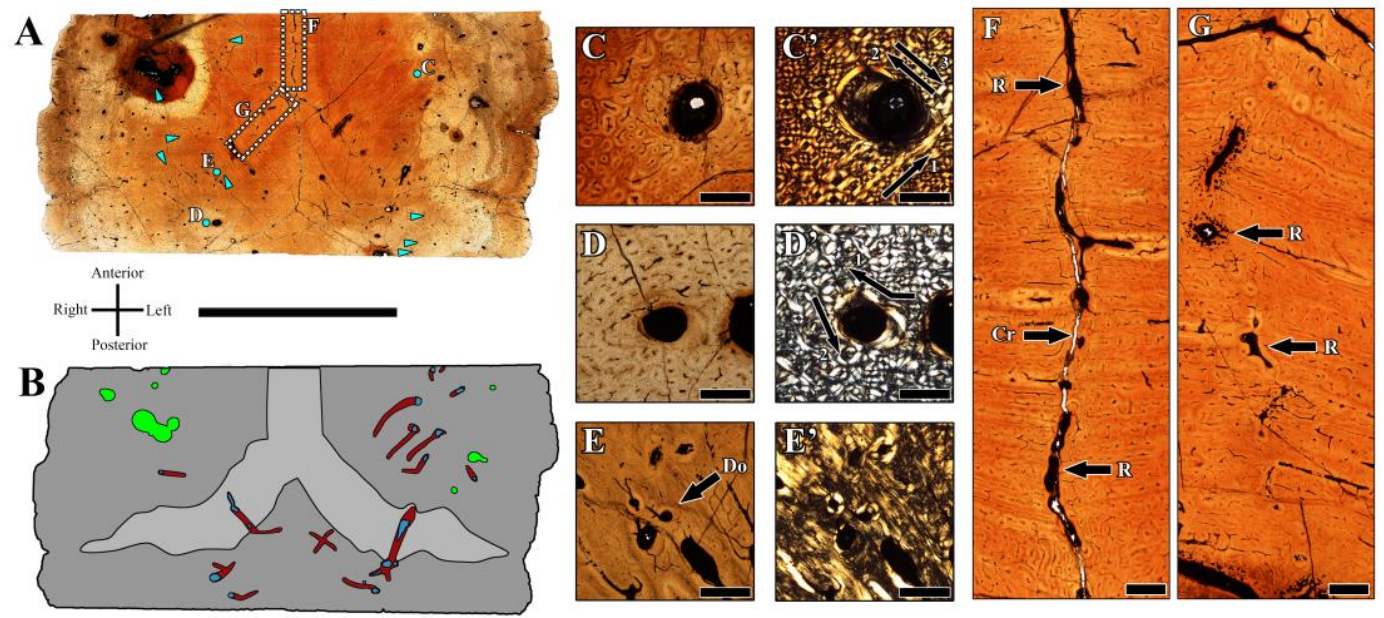

Figure 7. Shifted vascular canals, drifting osteons, and sutures of UALVP 8504. Notes: (A) UATSN 86 a horizontal plane section of UALVP 8504. Blue arrows indicate the position and orientation of drifting osteons. Scale bar $=2 \mathrm{~cm}$. (B) Simplified line drawing of UATSN 86. Light grey - ossified cambial layer (Bailleul \& Horner 2016); blue - shifted large vascular canals, red - secondary bone infilling the previous positions of the shifted vascular canals; green - Polykladichnus aragonensis. (C) A plugged canal demonstrating minute drift that is decoupled from growth, and alternation between secondary lamellar bone and fibrolamellar bone; under normal polarized light (NPL). (C') Same area under cross polarized light (CPL). Scale bars $=500 \mu \mathrm{m}$. (D) A drifting osteon that first drifted anterolaterally, and then posteromedially, under NPL. (D') Same area under CPL. The numbered arrows in C and D indicate the order and direction of drift. Scale bar $=500 \mu \mathrm{m}$. (E) A drifting osteon (Do) on the frontoparietal suture under NPL. (E') Same area under CPL. Scale bar $=500 \mu \mathrm{m}$. (F) Remodeling (R) along the internally fused interfrontal suture under NPL. Note a crack $(\mathrm{Cr})$ that traces the interfrontal suture, but extends beyond and into the parietal. Scale bar $=500$ $\mu \mathrm{m}$. (G) Remodeling along the internally fused frontoparietal suture under NPL. Scale bar $=500 \mu \mathrm{m}$.

The preservation of osteocyte lacunae in Zone II is generally associated with well-preserved primary vascular canals. Several randomly distributed patches of osteocyte lacunae preserve canaliculi (Fig. 5E). Large primary vascular canals occur throughout the parietal (Fig. 5A) but are more dorsally restricted in the frontal (Fig. $6 \mathrm{~A})$.

One dramatic deviation from the normal histological zonation of UALVP 8504 occurs in Zone II of the frontals, where large, bilateral vascular canals $(\sim 0.8 \mathrm{~mm}$ diameter $)$ are trailed (lateroventrally) by secondary parallel fibered bone, which appear to mark their previous positions (Fig. 6C, D). Zone II is typically devoid of any secondary remodeling (Goodwin \& Horner 2004; Evans et al. 2018). Jasinoski and Chinsamy
(2012) observed the same pattern around the mental foramina in the mandible of Tritylodon, where a trail of secondary bone had infilled each foramen's previous position. This relocation (though we prefer the term "shifting" to relocation, as relocation suggests a discrete, rather than continuous event) maintains an anatomical feature's position throughout growth (Enlow \& Harris 1964; eg. the mandible of Tritylodon grows from its posterior margin, so the mental foramen shifts posteriorly as the mandible grows). The shifting positions of the vascular canals in UALVP 8504 can be seen in the micro-CT images of the right frontal (Figs. 2, 3D), but are indistinguishable from the massive canals. These can be easily differentiated in thin-sections by the secondary bone trailing the shifting vascular canals. 

A

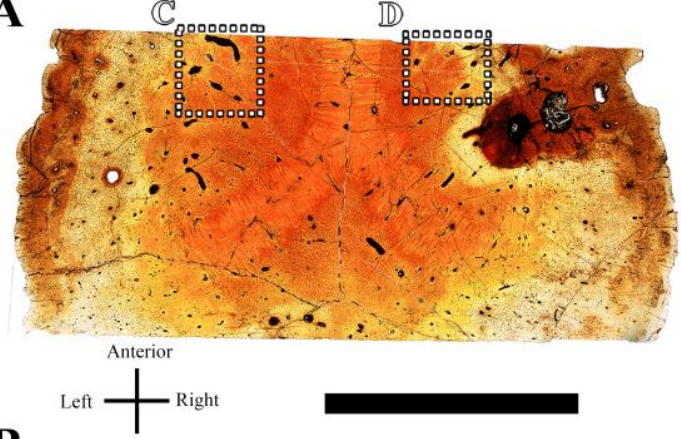

B

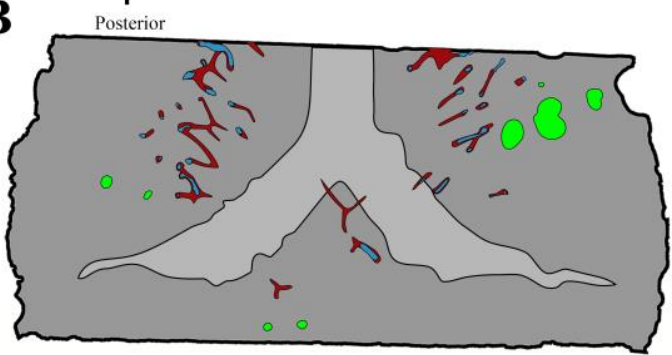

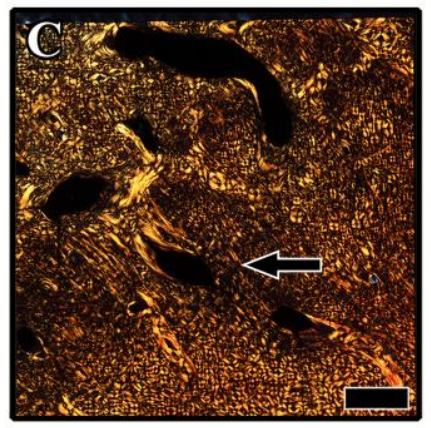

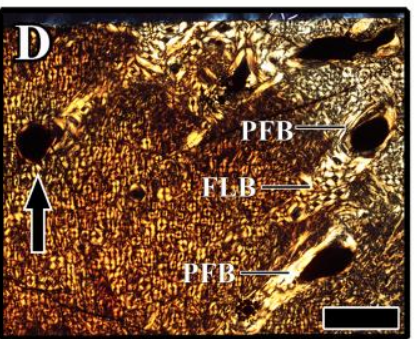

Figure 8. Shifted vascular canals in a horizontal section of UALVP 8504. Notes: (A) UATSN 87 - horizontal plane thin section through the center middle of the dome. Scale bar $=2 \mathrm{~cm}$. (B) Simplified line drawing of UATSN 87, highlighting the shifted vascular canals. Colours as in Fig. 7B.(C) Enlarged region of the shifted vascular canals in the left frontal under cross polarized light (CPL). Scale bar $=1 \mathrm{~mm}$. Arrow points to a shifted vascular canal that is decoupled from growth (shifting in the opposite direction of growth). (D) Enlarged region of the shifted vascular canals in the right frontal under CPL. Scale bar $=1 \mathrm{~mm}$. Arrow indicates a shifted vascular canal that is decoupled from growth. Note the secondary bone that trails the shifted vascular canals that begins with fibrolamellar bone and switches to parallel fibered bone. Abbreviations: FLB - fibrolamellar bone, PFB - parallel fibered bone.

The horizontal plane sections of UALVP 8504 reveal abundant dosoventrally oriented shifting vascular canals (Figs. 7,8), which have not been reported in previous frontoparietal histology studies. Shifting vascular canals appear more abundant in the frontals than the parietals, and more abundant in the more dorsal section (UATSN 87). The directions that these canals have shifted are mainly lateral or anterolateral in the frontals; however, some canals (in the frontals) show posteromedial shifting, posterior shifting, and posterolateral shifting (Fig. 8C, D). Unlike secondary osteons, these shifted vascular canals are generally "infilled" with fibrolamellar bone or parallel fibered bone (oriented along the direction of drift), and a few infilled areas alternate between these bone compositions (Figs. $7 \mathrm{C}, 8 \mathrm{D})$. The infilled area of one vascular canal in the right frontal (relocated posteromedially) is mainly filled with fibrolamellar bone and alternates between lamellar bone and parallel fibered bone near the open canal (Fig. 9E). Another vascular canal in the ventral section appears to have mainly relocated with growth (anterolateral), but then drifted roughly $580 \mu \mathrm{m}$ anteromedially, and then back on itself (posterolaterally) (Fig. 7C).

Additionally, the horizontal plane sections reveal drifting osteons (Figs. 7, 9), which differ from normal secondary osteons, where resorption strictly occurs longitudinally, by simultaneously resorbing in a transverse direction (Robling \& Stout 1999). In transverse section, semicircular lamellae (ie hemicyclic lamellae in Robling \& Stout 1999) form in the wake of the drifting canal (Fig. 9B, C). Although they appear grossly similar to the larger shifted vascular canals, drifting osteons strictly deposit bone on a resorption line, whereas the initial bone of the shifted vascular canals is deposited along the surface of the canals, not a resorption line (the primary bone is not truncated). New (secondary) bone is then deposited on the resorption line, truncating the surrounding primary bone that forms as the canal shifts. Drifting osteons have been reported in catarrhine primates (Robling \& Stout 1999), ungulates (Skedros et al. 2007), the mammaliform Tritylodon sp. (Jasinoski \& Chinsamy 2012), and pareiasaur parareptiles (Canoville \& Chinsamy 
2017). To our knowledge, these represent the first occurrence of drifting osteons in a diapsid.

Drifting osteons are more abundant in the dorsal horizontal section (UATSN 87, $\mathrm{n}=19$; UATSN $86, \mathrm{n}=10$ ). Over half of the drifting osteons in the dorsal section are situated on the junction of the dorsoventrally oriented primary vascular canals of Zone I, and the horizontally oriented primary vascular canals of the interfrontal (mediolaterally) and frontoparietal sutures (roughly anteroposterior) (Fig. 9A). The drifting osteons positioned at these boundaries are all directed (resorbing) towards the sutures. The few drifting osteons positioned farther away from the interfrontal and frontoparietal sutures show more variation in drift directions.

Only a pair of drifting osteons are positioned next to and resorbing towards the frontoparietal suture in the ventral horizontal section (Fig. 7A). A single drifting osteon is positioned along the frontoparietal suture (Fig. 7E). Most of the drifting osteons, however, show more variability in their orientations. One such drifting osteon in the parietals had initially drifted anterolaterally, and then revered its direction of drift posteromedially (Fig. 7D).

\section{Zone III}

Zone III is marked by the absence of large primary vascular canals, and the appearance of vascular canals with scalloped walls (Fig. 5B), which occur at the same depth as LAG 2. Vascular canals in Zone III remain abundant and radial, and are frequently lined with Howship's lacunae (Fig. $5 \mathrm{G})$, which are unique features of UALVP 8504 not seen in other pachycephalosaurid domes (Goodwin \& Horner 2004; Lehman 2010; Evans et al. 2018). Howship's lacunae are formed by the erosive activity of osteoclasts (Schultz 2001), and create a scalloped appearance in bone (Fig. 5G) This indicates that the enlargement of these primary vascular canals in Zone III occurred by resorption. The resorbing (enlarging) vascular canals do not extend as deep into the dome as the parietal depression. Neurovascular foramina are restricted to Zone III (Figs. 5A, 10A). Sharpey's fibers continue to the periosteal surface (Fig. $5 \mathrm{H})$. The periosteal surface is remarkably smooth, unlike the irregular surfaces of UALVP 49020 and UALVP 54399 (Fig. S1).

\section{Dorsal cortical depression histology}

The parietal depression truncates the primary fibrolamellar bone of the dome, including LAG 2 (Fig. 4A, B). The inclination of the lesion wall varies from moderate (UATSN 26) to slightly overhanging (UATSN 27), depending on the section. The floor of the depression generally follows the topography of normal dome growth. The depression floor is pitted twice on the left of the midline, and the pits correspond with the massive canals seen on the exterior surface and in micro-CT images (Figs. 2, 3). To the right of the midline, the lesion floor peaks before conforming to the margins of normal growth. The region on the right is more scalloped, and is the area with the external macroscopic "resorption" pits. The parietal lesions are not associated with any secondary bone deposition. A darker band below the periosteal surface is observable in planepolarized light (Fig. 5L), although it is likely caused by the thickness of the section in this region of the dome. Relatively small scallops (10$20 \mu \mathrm{m})$ along a flaking portion of the parietal depression appear to be Howship's lacunae (Fig. 10B). Well defined scallops are not present elsewhere along the lesion floor, or along any exterior surface. Although both UALVP 49020 and UALVP 54399 possess irregular surfaces, the irregularities on the surface of UALVP 49020 appear to be formed by exiting vascular canals (Fig. S2C). The surface of UALVP 54399 is macroscopically irregular, although microscopic scallops do not appear to be present upon closer examination (Fig. S3D). The depression, flaring canals, and dimpled pitting are all remarkably smooth and otherwise histologically indistinguishable from each other. 


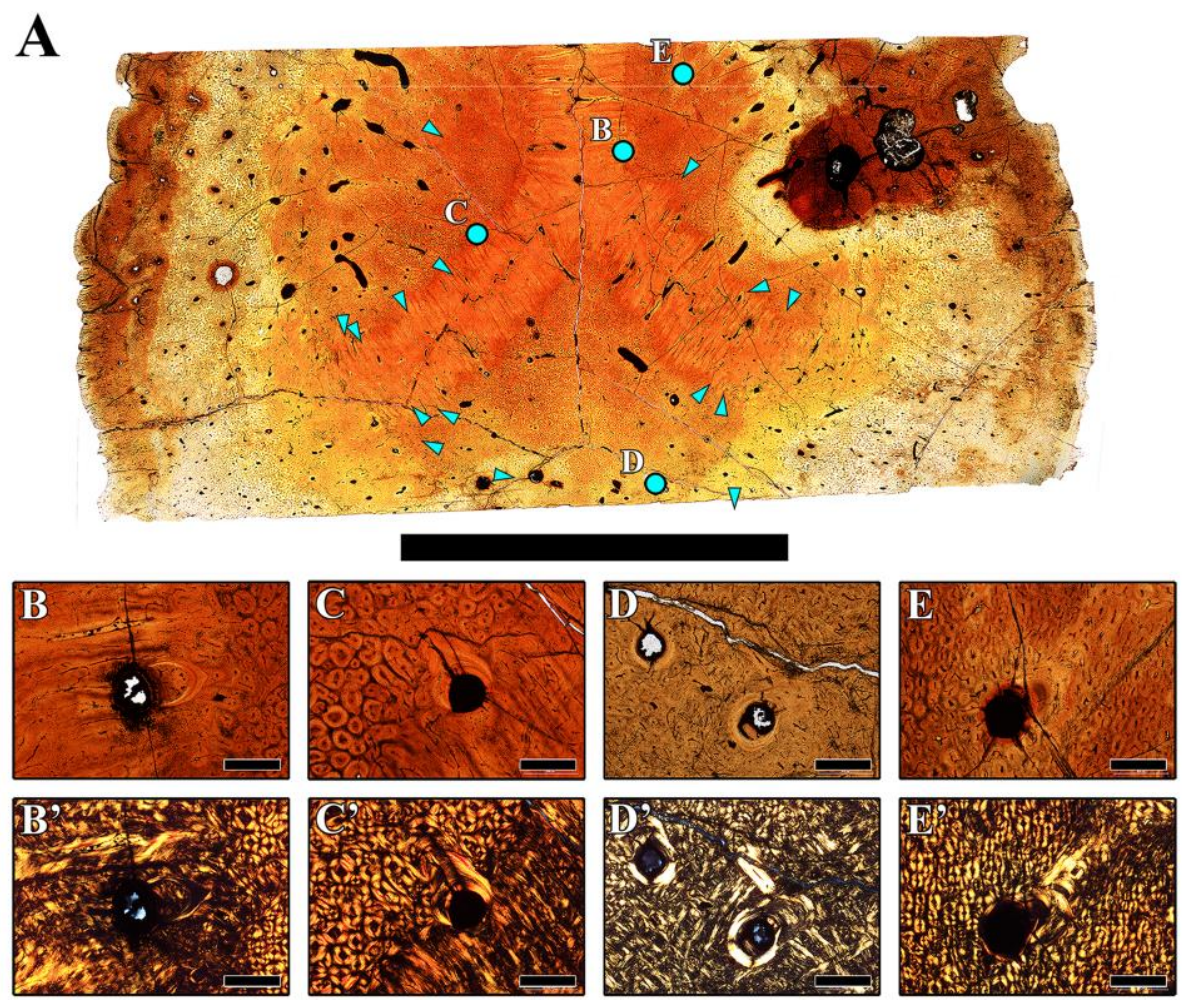

Figure 9. Drifting osteons in UALVP 8504. Notes: (A) UATSN 87. Scale bar $=2 \mathrm{~cm}$. Arrows indicate the position and orientation of drifting osteons. (B) A drifting osteon on the right side of the interfrontal suture, under normal polarized light (NPL). (B') Same area under cross polarized light (CPL). (C) A drifting osteon on the left frontal, drifting towards frontoparietal suture. (C') Same area under CPL. (D) A pair of drifting osteons in the parietal. Both have drifted away from the frontoparietal suture under NPL. (D') Same area under CPL. (E) A shifted vascular canal that is decoupled from growth under NPL. (E') Same are under CPL. Scale bars $=500 \mu \mathrm{m}$ for B-E.

Unfortunately, the frontal section (UATSN 28) was partially damaged during preparation, and the most dorsal apical surface is unusable for histological analysis. LAG 2 is present in an isolated region of the frontal section, having been truncated on both sides (Fig. 4F, G). This indicates external bone loss across most of the frontal, which otherwise appears to conform to normal dome morphology. Howship's lacunae are not observed along the frontal lesions.

\section{Discussion}

In order to be consistent with osteomyelitis, the pathologies on UALVP 8504 were hypothesised to possess reversal lines, secondary woven bone, and sclerotic bone. Previous studies identified these histopathological features in the lesions of pathological pachycephalosaur domes from higher energy conventional CT scans $(135 \mathrm{kV}$, $300 \mathrm{~mA}, 0.5 \mathrm{~mm}$ pixel resolution, and $0.5 \mathrm{~mm}$ thickness), which contributed to diagnosing post- traumatic osteomyelitis in those specimens (Peterson \& Vittore 2012; Peterson et al. 2013).

Surprisingly, the high-resolution micro-CT scans produced in this study $(100 \mathrm{kV}, 100 \mathrm{~mA}, 0.018$ $\mathrm{mm}$ pixel resolution, and $0.018 \mathrm{~mm}$ thickness) did not provide any information on the bone texture of UALVP 8504. The poor image contrast was likely the result of the low peak photon energies available using this model of benchtop x-ray microtomograph and were not of value to test the presence of the hypothesised histopathological features. Thin-sections are thus more suitable for this type of analysis. Several explanations for the discrepancy between these methodologies requires further investigation. One concern would be to better define the impact of $\mathrm{x}$-ray beam hardening upon surface features in conventional CT scans that had previously been interpreted as woven bone and sclerotic bone, as contrasted edge artefact will often result as the product of beam hardening. 
Alternatively, the differences may be due to the preservation of UALVP 8504, where vascular canals are infilled with a material of similar density to the bone, and not discernible from bone in micro-CT scans. As an alternative, high power synchrotron micro-CT (SR $\mu \mathrm{CT})$ imaging may better contrast and resolve histomorphometric features in these specimens, due to the ability to better tune monochromatic photon energies of significantly greater magnitude. At lower x-ray energies, higher contrast is often realised in computed tomography images, notably between loose (e.g., muscle) and dense (e.g., bony) tissues. That has been attributed to the photoelectric effect dominating linear $\mathrm{x}$-ray attenuation, thereby providing contrast based on tissue elemental composition. On the other hand, higher x-ray energies are dominated by Compton (inelastic) scatter, resulting in the scanned object's physical mass density serving as the prime determinant of attenuation (Fleckenstein et al. 2014).

Additionally, the micro-CT scans cannot be used to differentiate between the shifting blood vessels and the massive canals. These can be differentiated in thin-sections by the presence of secondary bone (blood vessels) and the absence of Howship's lacunae and secondary bone (massive canals), which allows for differentiation and 3D modeling in micro-CT scans (highlighting the advantage of utilizing both methods). The combination of bone truncation and the absence of Howship's lacunae demonstrate a postmortem origin for the massive canals, consistent with invertebrate borings. The boring structures of UALVP 8504 are branching, non-anatomizing, unlined tubes, which diagnoses the boring trace Polykladichnus aragonensis (Uchman \& Álvaro 2000). Uchman and Álvaro (2000) specify $P$. aragonensis bores are made vertically. Although the depositional (in situ) orientation of UALVP 8504 is unknown, isolated pachycephalosaur frontoparietal domes are hydrodynamically stable on their dorsal and ventral surfaces (Peterson \& Bigalke 2013). Therefore, it is likely that these borings were made vertically, although the direction of branching cannot be determined. Invertebrate borings have also been suggested in other frontoparietal specimens: TMP1972.027.0001 (the type specimens of Gravitholus albertae; Sullivan 2003), and TMP2004.300.0001 (cf. Pachycephalosaurus; Evans et al. 2015).

\section{Differential diagnosis}

Thin-sections of UALVP 8504 reveal its lesions possess no secondary woven bone or sclerotic bone. The absence of these features falsifies the diagnosis of osteomyelitis (sensu Peterson \& Vittore 2012). Modern reptiles may respond to osteomyelitis with mild periosteal and proliferative reactions (Silverman 2006), which has influenced some interpretations of non-avian dinosaur pathologies (eg. Matthias et al. 2016). However, mounting evidence suggests that nonavian dinosaurs responded to bone infections with reactive bone growth (García et al. 2016; Hunt et al. 2019; Siviero et al. 2020). Previously studied pathological domes that showed suspected reactive secondary bone (e.g. BMR P2001.4.5, Peterson \& Vittore 2012; and TMP1979.014.0853, Peterson et al. 2013) were scanned with slices $0.5 \mathrm{~mm}$ thick. Micro-CT scans (17.8 $\mu \mathrm{m}$ thickness) of UALVP 8504 did not show this same pattern. It is possible that the observed patterns in previously studied specimens are artefacts of their larger sizes and/or the low resolution of CT scans. However, reactive woven bone has been identified from thin sections of pathological domes (Weaver et al. 2014), although these specimens require further detailed study.

The scalloped surface along the posterior lesion floor may represent Howship's lacunae (Fig. 10). Although these - as well as the Howship's lacunae observed within some vascular canals in Zone III - appear too small for Howhsip's lacunae (which typically reflect the size of the large, multinucleated osteoclasts), Howship's lacunae have been reported at similar sizes to the scallops observed on the parietal lesion (Boyde \& Hobdell 1968; Fig. 2.7C in Huttenlocker et al. 2013). Furthermore, Boyde and Hobdell (1968) reported two size classes of Howship's lacunae, with the smallest class approximately $12 \mu \mathrm{m}$ wide. They speculated that the smaller class may have formed by mononucleated cells; both mononucleated monocytes (Mundy et al. 1977) and macrophages (Teitelbaum et al. 1979) are capable of resorbing bone. The absence of Howship's lacunae in weathered (UALVP 54399) and non-pathological (UALVP 49020) specimens further corroborates the pathological origins of the lesions in UALVP 8504 (Appendix S1). Howship's lacunae likely have a low preservation potential on external surfaces due to their small size. At such small scales, abrasion and loss of Howship's lacunae would likely be unrecognizable in thin-sections. This would explain why they are rarely observed on the lesions of UALVP 8504. Alternatively, the 
scalloped margin observed in this study may have formed by sediment abrasion (Thompson et al.
2011), and the flaking of the underlying bone may support an abrasive origin.
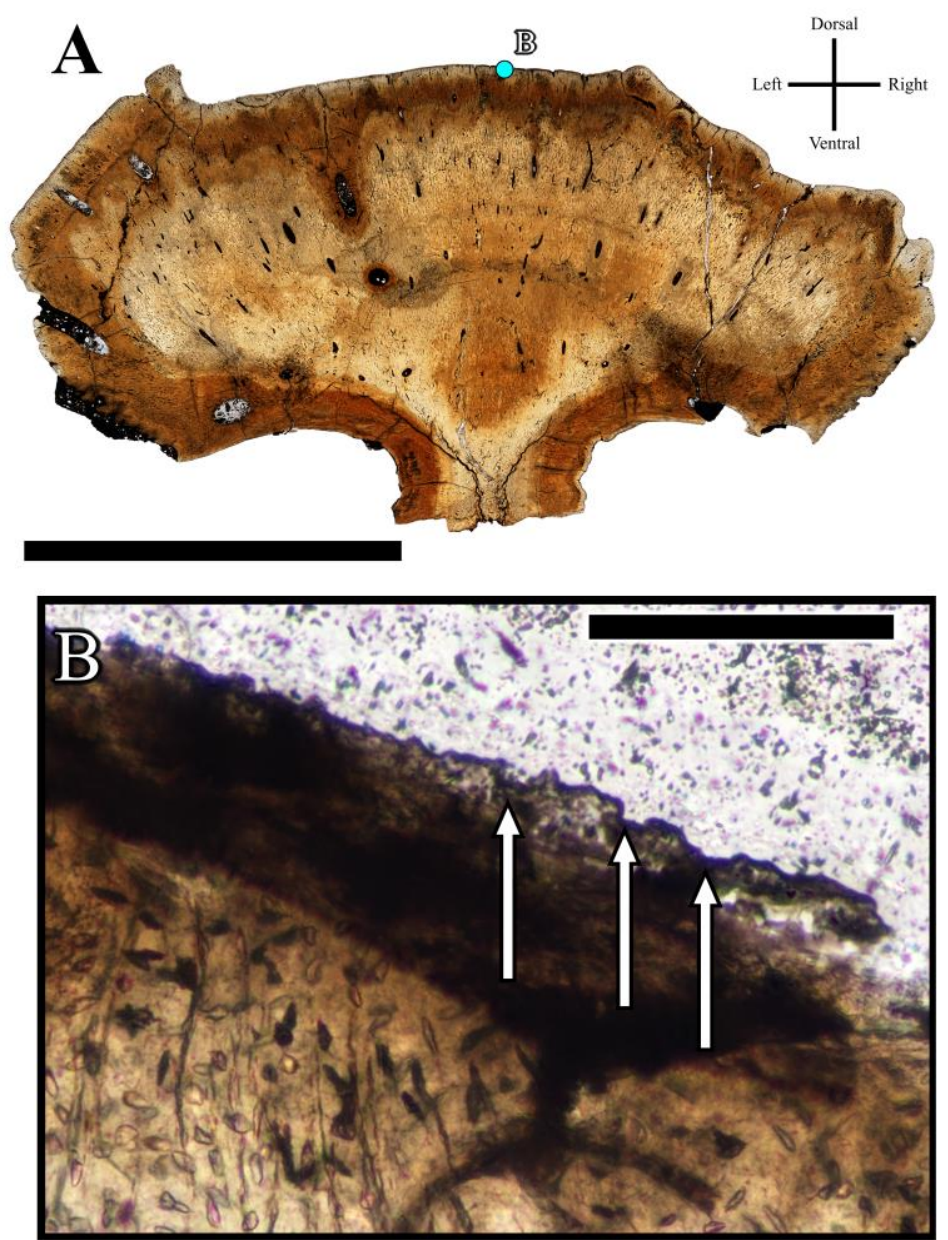

Figure 10. Suspected evidence of bone resorption in UALVP 8504. Notes: (A) UATSN 27 - parietal thinsection. Scale bar $=2 \mathrm{~cm}$. (B) Suspected Howship's lacunae (arrows) line part of the lesion floor. Scale bar $=$ $100 \mu \mathrm{m}$.

The Howship's lacunae lining vascular canals in Zone III of UALVP 8504 is a novel histological feature not reported in previous pachycephalosaur histological studies. Given that these scalloped vascular canals extend nearly as deep into the dome as the lytic lesion does, pathological resorption may have initiated within primary vascular canals near the cortical surface, coalescing to form the large depressive lesions. However, a detailed frontoparietal histological analysis of Foraminacephale brevis is required to confirm that this is not a normal feature of dome growth.

The combined morphology and histology of the lesions of UALVP 8504 are not diagnostic, but are similar to both post-traumatic and non-traumatic lesions. Ulcerating shell disease/ulcerating dermatitis in turtles can form after bacteria/fungi colonize shell damage (Wallach 1975; Harkewicz 2001; Maas 2013), and is suspected to form from environmental toxins (Garner et al. 1997). Bony changes involved in cases of ulcerative shell disease of an unknown origin began with osteolysis (Lovich et al. 1996). Chronic cases develop nodule growths comprised of secondary woven and lamellar bone, and thickened trabeculae (Garner et al. 1997). The prechronic/lytic stage is consistent with the lesions affecting UALVP 8504. The overlying horny epidermal keratin of turtle shells (Barten 2006) may be analogous to the suspected keratinous covering to pachycephalosaur domes 
(Hieronymus et al. 2009). However, future histological studies should describe and compare traumatic injuries of modern bovids sustained during rutting to pachycephalosaur cranial pathologies, which would provide crucial comparisons to animals known to engage in "head-butting" intraspecific behaviour.

Post-traumatic lesions of similar morphology and histopathology (absence of reactive woven bone) appear in ankylosaurid osteoderms, and were considered consistent with (although not diagnostic to) ulcerative dermatitis (Matthias et al. 2016). These pathologies were also thin sectioned; secondary bone was not identified in or around the lesions. Matthias et al. (2016) suggested these lesions may have formed by either osseous ulceration, or by pressure erosion from granulomas (which encapsulate necrotic tissue) within the dermis. Post-traumatic epidermal inclusion cysts also produce lytic lesions (Bobra et al. 1964). However, this is unlikely given the presence of multiple depressions of UALVP 8504, which would require several traumatic events to independently dislodge squamous epithelium along the frontoparietal. Non-traumatic, multifocal lytic lesions can result from multiple myeloma (Hameed et al. 2014), metastatic carcinoma (Marks \& Hamilton 2007), Langerhans cell histiocytosis (Favara et al. 1997), and leukemia (Ortner 2003). Differential diagnoses for these were reviewed by Riccomi et al. (2019): Langerhans cell histiocytosis and leukemia typically affect children and young adults, whereas multiple myeloma and metastatic carcinoma typically affect people $>40$ years of age. The skull is the most frequently affected element in Langerhans cell histiocytosis and leukemia, whereas multiple myeloma and metastaic carcinoma affect vertebrae and ribs more frequently than the skull. Multiple myeloma lytic lesions are discrete, and are 5-20 mm. However, lesions of UALVP 8504 appear to have merged. Metastatic carcinoma lesions vary from elliptical to irregular in shape, and may additionally be proliferative or mixed lesions. Leukemia may be expressed as abundant, welldefined pits or form continuous fronts of bone lysis. Langerhans cell histiocytosis lesions are round to oval with beveled edges; multiple lesions may coalesce. Nutritional stress has been suggested to form lytic lesions on the surfaces of bovid horns (Clutton-Brock et al. 1990; Kierdorf et al. 2016). Although pachycephalosaur skeletons are extremely rare (Evans et al. 2013), the skeletal distribution of pathologies (if present) would aid in evaluating these non-traumatic pathologies.

\section{Alternative histological evidence of behaviour}

Although the morphological and histological features of the lesions in UALVP 8504 are not diagnostic, additional unanticipated histological features - the non-anterolateral shifting vascular canals in the frontals, and the drifting osteonsprovide insight into the origin of the lesions. If the shifted vascular canals in the frontals were coupled with growth, then all these vascular canals should show anterolateral shifting. However, not all these vascular canals were shifted anterolaterally, with some shifting in the opposite direction (medioposterioraly), and others exhibit predominant anterolateral shifts with minor shifting in different directions into their current positions (e.g., Fig. 7C). This indicates that some of the shifted vascular canals were decoupled from growth, and were responding to alternative stimuli.

Drifting osteons are frequently oriented (resorbing) towards the endosteum in Homo sapiens ribs and tibiae (Epker \& Frost 1965; Burnton et al. 1989). This follows a gradient in strain magnitude created when such bones are bent (Skedros et al. 1997). Similarly, concentrations of drifting osteons were observed along the interface of primary and secondary bone in H. sapiens ilia (Schnitzler 2015), an expected area to produce a gradient in strain magnitude (higher strain in primary bone). Furthermore, simulation studies have replicated the formation of drifting osteons, whereby resorption is oriented down the strain gradient (ie. resorbing away from maximum strain) (van Oers et al. 2008; van Oers et al. 2014). Thus, the presence of drifting osteons in UALVP 8504 indicates that the dome was strained during life, and that strain was not evenly distributed. It is possible that the shifted vascular canals that are decoupled from growth had shifted the open vascular canals in localized areas that experienced higher strain.

Drifting osteons are more abundant in the dorsal horizontal plane of section (UATSN 87), compared to the ventral coronal plane section (UATSN 86). This suggests that strain generally increased dorsally through the dome. The dorsal horizontal plane of section also contained drifting osteons positioned alongside the interfrontal and frontoparietal sutures that had all been drifting towards their respective sutures. This would 
indicate that the ossified cambial layer (Bailleul \& Horner 2016) had experienced relatively lower intensities of strain than the surrounding bone. Muscle induced strain would not have affected the frontals (where half of the total number of drifting osteons are located), as no large muscles would have inserted onto the frontals. The only other explanation is through external mechanical loading.

In Finite Element Analyses of a Pachycephalosaurus dome, simulated impacts created strain vectors that radiate inwards from the impact site, and are most intense immediately under the impact (Snively \& Cox 2008). Thus, a strain gradient is formed through the dome where the maximum strain is along the midline (Fig. 11A). However, this simulated strain gradient is the opposite of the gradient inferred by the orientation of drifting osteons (assuming an impact to the dome apex), which indicates that strain was less intense along the ossified cambial layers of the frontoparietal and interfrontal sutures relative to the surrounding bone.
A
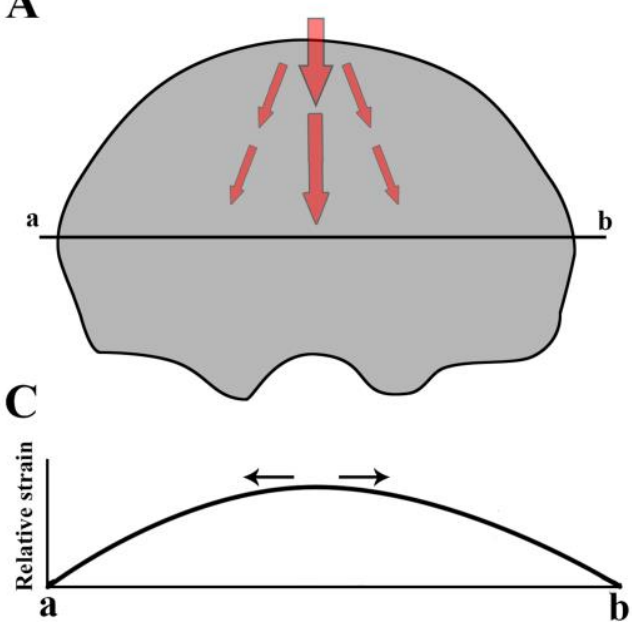

B
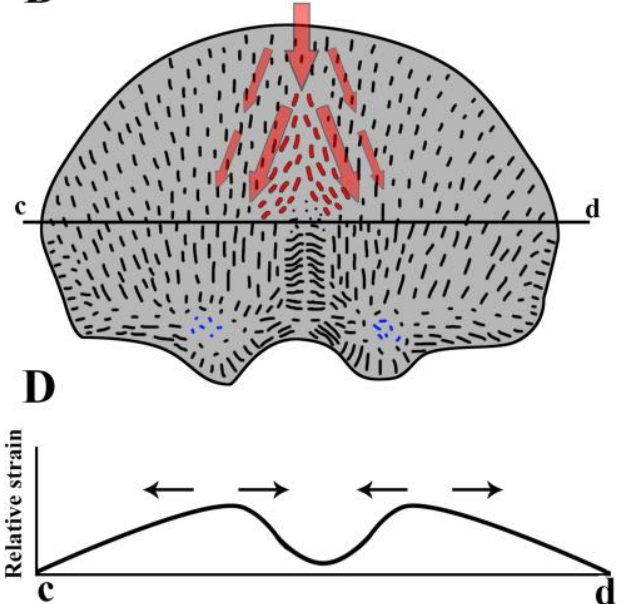

Figure 11. Hypothesized strain vectors and intensities sustained from a dorsal impact to the dome. Notes: (A) A simplified model of a pachycephalosaur frontoparietal dome. Red arrows indicate the magnitude and orientation of strain vectors based on the uniform density FEA model in Snively and Cox (Snively \& Cox 2008). (B) A simplified model of a pachycephalosaur frontoparietal dome including vascular canals. Vascular orientation based on UATSN 28. Red lines depict the dorsomedially oriented vasculature. The red arrow depicts the hypothetical path that strain may follow the dorsomedially oriented vasculature. (C) The relative hypothetical strain intensities across a horizontal section of the model in A. Strain is most intense sagittally and decreases laterally. Arrows depict the direction that drifting osteons would drift across the horizontal plane. (D) The relative strain intensities across a horizontal section of the model in B. The dorsoventrally oriented canals direct strain laterally, away from the interfrontal suture. This creates two regions of maximum strain parasagittal to the interfrontal suture, and a region or relatively lower strain at the interfrontal suture. Arrows indicate the directions that drifting osteons would be oriented, consistent with the observed orientations of drifting osteons in UALVP 8504.

The interfrontal and frontoparietal sutures would have been obvious areas of weakness if the dome apex sustained an impact. The coronal plane of section across the frontals shows that the vasculature dorsal to the interfrontal suture is not oriented dorsoventrally, but is directed dorsomedially. If the dome apex sustained an impact, these vessels may have directed strain laterally, away from the suture (Fig. 11B). This would produce an area of relatively less strain along the interfrontal suture, and areas of higher strain lateral to the suture. This strain gradient is consistent with the direction of the drifting osteons along the margins of the interfrontal suture. Similar vasculature may have been positioned dorsal to the frontoparietal suture as well. Future biomechanical tests of the frontoparietal dome should consider incorporating vascular orientation into FEA to test this hypothesis. 
The presence of drifting osteons, and to a lesser extent the shifted vascular canals decoupled from growth vectors demonstrate that UALVP 8504 sustained mechanical loading to the apex of the dome, likely induced by an impact or more likely multiple impacts and is consistent with the headbutting hypothesis. These impacts could have traumatized the dome, and led to the development of the ulcerative dermatitis (although not diagnosed in UALVP 8504). Although we disagree with the previous diagnoses of posttraumatic osteomyelitis (Peterson \& Vittore 2012; Peterson et al. 2013), this study supports their conclusions regarding the behavioural and evolutionary significance of the dome.

\section{Conclusions}

Peterson et al. (2013) argued the high frequency of (what they interpreted as) post-traumatic osteomyelitis in pachycephalosaur frontopareital domes was consistent with the head-butting hypothesis. The dome must have had a high benefit to fitness, considering the high physiological demands of growing the dome and battling frequent infections of injuries sustained during combat. These two points led Peterson et al. (2013) to argue the dome was most likely the result of sexual selection, whereby members of a species competed in head-butting duels for mate or territory acquisition.

Thin-sections of UALVP 8504 drastically outperform micro-CT scans in histopathological analysis. Howship's lacunae on the lesions of UALVP 8504 confirm the lesions are indeed pathological, and eliminate post-mortem processes for explanations. The histopathological features previously identified in CT scans of other pathological domes are clearly absent in thinsections, falsifying the diagnoses as osteomyelitis. Horizontal sections reveal shifted vascular canals and drifting osteons, which are reported for the first time in a pachycephalosaur dome and demonstrate the benefit of thin-sectioning domes in multiple orientations. Shifted vascular canals decoupled from growth vectors and the drifting osteons demonstrate that the dome apex had sustained external mechanical loading, consistent with head-butting, and that the interfrontal and frontoparietal sutures experienced relatively lower magnitudes of strain, compared to the surrounding bone. The external mechanical loading may have been sufficient to damage the overlying soft tissue, in which case the lesions of UALVP 8504 likely represent incidences of posttraumatic ulcerative dermatitis. Therefore,
UALVP 8504 likely engaged in head-butting combat and suggest the pathologies in pachycephalosaur domes formed in response to trauma. The conclusions of Peterson et al. (2013) are in part supported by histology (drifting osteons), although diagnosis of these pathologies will require further histopathological analyses.

\section{Acknowledgments}

We would like to thank Tobe Bond, Pamella Correia, Gregory Funston, Mark Powers, Matthew Rhodes, Caroline Sinclair, and the late George Pemberton for discussions and their scientific input, and Clive Coy for his assistance in casting and moulding. We would also like to thank the two anonymous reviewers, whose comments greatly improved the quality of this manuscript. NSERC and the Killam Trust supported this research through grants to ARHL (Isaak Walton Killam Memorial Postdoctoral Fellowship, NSERC Postdoctoral Fellowship) and PJC (NSERC Discovery grant number RGPIN-2017-04715).

\section{Disclosure statement}

No potential conflict of interest was reported by the authors

\section{References}

Bailleul, A.M., \& Horner, J.R. (2016). Comparative histology of some craniofacial sutures and skull-base synchondroses in non-avian dinosaurs and their extant phylogenetic bracket. J Anat. 229(2), 252-285. https://doi.org/10.1111/joa.12471

Bailleul, A.M., O’Connor, J., \& Schweitzer, M.H. (2019). Dinosaur paleohistology: Review, trends and new avenues of investigation. PeerJ. 7(e7764). https://doi.org/10.7717/peerj.7764

Barten, SL. (2006). Shell Damage. In: Mader DR, editor. Reptil Med Surg [Internet]. Second Edi. [place unknown]: Elsevier Inc.; p. 893-899. http://dx.doi.org/10.1016/B0-72169327-X/50071-7

Bermúdes de Castro, J.M. (1988). Dental diseases and Harris lines in the fossil human remains from Atapuerca-Ibeas (Spain). J Paleopathol. 1(3):131-146.

Bobra, S.T., Matzinger, K., \& McCluskey, L.U. (1964). Epidermoid cyst of the terminal phalanx of the thumb. Can Med Assoc J., 90,1464-1466. 
De Boer, H.H., Van der Merwe, A.E., \& Maat, G.J.R. (2013). The diagnostic value of microscopy in dry bone palaeopathology: A review. Int J Paleopathol., 3(2),113-121. https://doi.org/10.1016/j.ijpp.2013.03.0 04

Boyde, A., \& Hobdell, M.H. (1968). Scanning electron microscopy of lamellar bone. Zeitschrift für Zellforsch und Mikroskopische Anat., 93(2), 213-231. https://doi.org/10.1007/BF00336690

Brown, B,. \& Schlaikjer, E.M. (1943). A study of the troodont dinosaurs with the description of a new genus and four new species. Bull Am Museum Nat Hist., 82,115-150.

Burnton, P., Nyssen-Behets, C., \& Dhem, A. (1989). Haversian bone remodeling in human fetus. Acta Anat (Basel)., 135, 171-175.

Cabral, U.G.,, Riff D., Kellner, A.W.A., \& Henriques, D.D.R. (2011). Pathological features and insect boring marks in a crocodyliform from the Bauru Basin, Cretaceous of Brazil. Zool J Linn Soc., 163 , https://doi.org/10.1111/j.10963642.2011.00715.x

Calhoun, J.H., \& Manring, M.M. (2005). Adult osteomyelitis. Infect Dis Clin North Am. 19(4), 765-786. https://doi.org/10.1016/j.idc.2005.07.00 9

Canoville, A., \& Chinsamy, A. (2017). Bone microstructure of pareiasaurs (Parareptilia) from the Karoo Basin, South Africa: Implications for growth strategies and lifestyle habits. Anat Rec., 300(6), 1039-1066. https://doi.org/10.1002/ar.23534

Clutton-Brock, J., Dennis-Bryan. K., Armitage, P.L., \& Jewekk. P.A. (1990). Osteology of the Soay sheep. Bull Br Museum, Nat Hist Zool., 56(1), 1-56.

Enlow, D.H., \& Harris, D.B. (1964). A study of the postnatal growth of the human mandible. Am J Orthod., 50(1), 25-50. https://doi.org/10.1016/S00029416(64)80016-6

Epker, B.N., \& Frost, H.M. (1965). The direction of transverse drift of actively forming osteons in human rib cortex. J Bone $\mathrm{Jt}$ Surg., 47(6), 1211-1215.

Evans, D.C., Brown, C.M., Ryan, M.J., \& Tsogtbaatar, K. (2011). Cranial ornamentation and ontogenetic status of Homalocephale calathocercos (Ornithischia: Pachycephalosauria) from the Nemegt Formation, Mongolia. J Vertebr Paleontol., 31(1), 84-92. https://doi.org/10.1080/02724634.2011. 546287

Evans, D.C., Hayashi, S., Chiba, K., Watabe, M., Ryan, M.J., Lee, Y.N., Currie, P.J., Tsogtbaatar, K., \& Barsbold, R. 2018. Morphology and histology of new cranial specimens of Pachycephalosauridae (Dinosauria: Ornithischia) from the Nemegt Formation, Mongolia. Palaeogeogr Palaeoclimatol Palaeoecol [Internet]. 494:121-134.

http://dx.doi.org/10.1016/j.palaeo.2017. 11.029

Evans, D.C., Schott, R.K., Larson, D.W., Brown, C.M., Ryan, M.J. (2013). The oldest North American pachycephalosaurid and the hidden diversity of small-bodied ornithischian dinosaurs. Nat Commun. 4, 1828. https://doi.org/10.1038/ncomms2749

Evans, D.C., Vavrek, M.J., \& Larsson, H.C.E. (2015). Pachycephalosaurid (Dinosauria: Ornithischia) cranial remains from the latest Cretaceous (Maastrichtian) Scollard Formation of Alberta, Canada. Palaeobiodiversity and Palaeoenvironments., 95, 579-585. http://dx.doi.org/10.1007\%2Fs12549015-0188-x

Favara, B.E., Feller, A.C., Pauli, M., Jaffe, E.S., Weiss, L.M., Arico, M., Bucsky, P., Egeler, R.M., Elinder, G., Gadner, H., et al. (1997). Contemporary classification of histiocytic disorders. Med Pediatr Oncol. 29(3):157-166. https://doi.org/10.1002/(SICI)1096911X(199709)29:3\%3C157::AIDMPO1\%3E3.0.CO;2-C

Fleckenstein, P., Tranum-Jensen, J., \& Myschetzky, P.S. (2014). Anatomy in Diagnostic Imaging (3rd ed). Chrichester: John Whiley \& Sons.

Galton, P.M. (1971). A primitive dome-headed dinosaur (Ornithischia: Pachycephalosauridae) from the Lower Cretaceous of England and the function of the dome of pachycephalosaurids. J Paleontol., 45(1), 40-47.

García, R.A., Cerda, I.A., Heller, M.M., Rothschild, B.M., \& Zurriaguz, V. 
(2016). The first evidence of osteomyelitis in a sauropod dinosaur. Lethaia, 50, 227-236. https://doi.org/10.1111/let.12189

Garner, M.M., Herrington, R., Howerth, E.W., Homer, B.L., Nettles, V.F., Isaza, R., Shotts, E.B. (Jr), Jacobson, E.R. (1997). Shell disease in river cooters (Pseudemys concinna) and yellowbellied turtles (Trachemys scripta) in a Georgia (USA) lake. J Wil., 33(1), 7886. https://doi.org/10.7589/0090-355833.1 .78

Geist, V. (1966). The evolution of horn-like organs. Behaviour, 27(3/4), 175-214. https://doi.org/10.1163/156853966X001 55

Gilmore, C.W. (1924). On Troodon validus, an orthopodous dinosaur from the Belly River Cretaceous of Alberta, Canada. Univ Alberta, Dep Geol Bull 1.:1-43.

Goodwin, M.B., Buchholtz, E.A., \& Johnson, R.E. (1998). Cranial anatomy and diagnosis of Stygimoloch spinifer (Ornithischia: Pachycephalosauria) with comments on cranial, display structures in agonistic behavior. J Vertebr Paleontol. 18(2), 363-375. https://doi.org/10.1080/02724634.1998. 10011064

Goodwin, M.B., \& Horner, J.R. (2004). Cranial histology of pachycephalosaurs (Ornithischia: Marginocephalia) reveals transitory structures inconsistent with head-butting behavior. Paleobiology, $30(2)$, 253-267. https://doi.org/10.1666/00948373(2004)030\%3C0253:CHOPOM\%3 E2.0.CO;2

Haines, R.W., \& Mohuiddin, A. (1968). Metaplastic bone. J Anat [Internet]. 103(3):527-38.

http://www.ncbi.nlm.nih.gov/pubmed/5 683997\%0Ahttp://www.pubmedcentral. nih.gov/articlerender.fcgi?artid=PMC12 31669

Hameed, A., Brady, J.J., Dowling, P., Clynes, M., \& O'Gorman, P. (2014). Bone disease in multiple myeloma: pathophysiology and management. Cancer Growth Metastasis, 7, 33-42. https://doi.org/10.4137\%2FCGM.S1681 7

Harkewicz, K.A. (2001). Dermatology of reptiles: A clinical approach to diagnosis and treatment. Vet Clin North Am - Exot
Anim Pract, 4(2), 441-461. http://dx.doi.org/10.1016/S10949194(17), 30039-7

Hieronymus, T.L., Witmer, L.M., Tanke, D.H., \& Currie, P.J. (2009). The facial integument of centrosaurine ceratopsids: Morphological and histological correlates of novel skin structures. Anat Rec, 292(9), 1370-1396. https://doi.org/10.1002/ar.20985

Hone, D.W.E., Tanke, D.H. (2015). Pre- and postmortem tyrannosaurid bite marks on the remains of Daspletosaurus (Tyrannosaurinae: Theropoda) from Dinosaur Provincial Park, Alberta, Canada. PeerJ, 3, e885. https://doi.org/10.7717/peerj.885

Horner, J.R., Goodwin, M.B. (2009). Extreme cranial ontogeny in the upper cretaceous dinosaur Pachycephalosaurus. PLoS One, 4(10), e7627. https://doi.org/10.1371/journal.pone.000 7626

Hunt, T.C., Peterson, J.E., Frederickson, J.A., Cohen, J.E., \& Berry, J.L. (2019). First documented pathologies in Tenontosaurus tilletti with comments on infection in non-avian dinosaurs. Sci Rep, 9(8705), 1-8. https://doi.org/10.1038/s41598-01945101-6

Huttenlocker, A.K., Woodward, H., \& Hall, B.K. (2013). The Biology of Bone. In: Padian $\mathrm{K}$, Lamm E-T, editors. Bone Histol Foss Tetrapods Adv Methods, Anal Interpret. University of California Press; p. 13-34.

Jasinoski, S.C., \& Chinsamy, A. (2012). Mandibular histology and growth of the nonmammaliaform cynodont Tritylodon. J Anat, 220(6), 564-579. https://doi.org/10.1111/j.14697580.2012.01494. $\mathrm{x}$

Kierdorf, U., Meng, S., \& Kahlke, R. (2016). Resorptive depressions on a horn core of Late Pleistocene (MIS 3) Bison priscus (Bovidae, Mammalia) from northeastern Germany. Int J Paleopathol. 15, 76-82. https://doi.org/10.1016/j.ijpp.2016.08.0 06

Lambe, L,M. (1902). New genera and species from the Belly River series (MidCretaceous). Contrib to Can Paleontol Geol Surv Canada. 3, 25-81.

Lambe, L.M. (1918). The Cretaceous genus Stegoceras, typifying a new family referred provisionally to the Stegosauria. 
Trans R Soc Canada, 12, 23-36.

Landry, S.O. (1995). Stegoceras not a headbutter. Am Zool, 35(5), 60A.

Lehman, T.M. (2010). Pachycephalosauridae from the San Carlos and Aguja Formations (Upper Cretaceous) of West Texas, and observations of the frontoparietal dome. J Vertebr Paleontol, 30(3), 786-798. https://doi.org/10.1080/0272463100376 3532

Longrich, N.R., Sankey, J., \& Tanke, D. (2010). Texacephale langstoni, a new genus of pachycephalosaurid (Dinosauria: Ornithischia) from the upper Campanian Aguja Formation, southern Texas, USA. Cretac Res., 31(2), 274-284. https://doi.org/10.1016/j.cretres.2009.12 .002

Lovich, J.E., Gotte, S.W., Ernst, C.H., Harshbarger, J.C., Laemmerzahl, A.F., \& Gibbons. J.W. (1996). Prevalence and histopathology of shell disease in turtles from Lake Blackshear, Georgia. J Wildl Dis, 32(2), 259-265. https://doi.org/10.7589/0090-355832.2.259

Maas, AK. (2013). Vesicular, ulcerative, and necrotic dermatitis of reptiles. Vet Clin North Am - Exot Anim Pract, 16(3), 737-755.

http://dx.doi.org/10.1016/j.cvex.2013.05 .007

Mallon, J.C., \& Evans, D.C. (2014). Taphonomy and habitat preference of North American pachycephalosaurids (Dinosauria, Ornithischia). Lethaia, 47(4), 567-578. https://doi.org/10.1111/let.12082

Marks, M.K., \& Hamilton, M.D. (2007). Metatatic carcinoma: palaeopathology and differential diagnosis. Int $\mathbf{J}$ Osteoarchaeol. 17, 217-234. https://doi.org/10.1002/oa.874

Maryańska, T. (1990). Pachycephalosauria. In: Weishampel DB, Dodson P, Osmólska H, editors. Dinosaur. 1st ed. Berkley: University of California Press; p. 564 577.

Maryańska, T., Chapman, R.E., \& Weishampel, D.B. (2004). Pachycephalosauria. In: D.B. Weishampel, P. Dodson, \& H. Osmólska (Eds). Dinosaur (2nd ed). Berkley: University of California Press.

Maryańska, T., \& Osmólska, H. (1974). Pachycephalosauria, a new suborder of ornithischian dinosaurs. Palaeontol Pol. 30, 45-102.

Matthias, A.E., McWhinney, L.A., \& Carpenter, K. (2016). Pathological pitting in ankylosaur (Dinosauria) osteoderms. Int J Paleopathol. 13, 82-90. https://doi.org/10.1016/j.ijpp.2016.02.0 06

Mundy, G.R., Altman, A.J., Gondek, M.D., \& Bandelin, J.G. (1977). Direct resorption of bone by human monocytes. Science, 196(4294), 1109-1111. https://doi.org/10.1126/science.16343

van Oers, R.F.M., Klein-Nulend, J., \& Bacabac, R.G. (2014). The osteocyte as an orchestrator of bone remodeling: An engineer's perspective. Clin Rev Bone Miner Metab. 12(1), 2-13. https://doi.org/10.1007/s12018-0149154-9

van Oers, R.F.M., Ruimerman, R., van Rietbergen, B., Hilbers, P.A.J., Huiskes, R. (2008). Relating osteon diameter to strain. Bone, 43(3), 476-482. https://doi.org/10.1016/j.bone.2008.05.0 15

Ortner, D.J. (2003). Identification of Pathological Conditions in Human Skeletal Remains $\left(2^{\text {nd }} e d\right)$. San Diego CA: Academic Press.

Pardo-Pérez, J.M., Kear, B.P., Gómez, M., Moroni, M., \& Maxwell, E.E. (2018). Ichthyosaurian palaeopathology: evidence of injury and disease in fossil 'fish lizards.' J Zool, 304(1), 21-33.

Perle, A., Maryańska, T., \& Osmólska, H. (1982). Goyocephale lattimorei gen. et sp. n., a new flat-headed pachycephalosaur (Ornithischia, Dinosauria) from the Upper Cretaceous of Mongolia. Acta Palaeontol Pol, 27(1-4), 115-127.

Peterson, J.E., \& Bigalke, C.L. (2013). Hydrodynamic behaviors of pachycephalosaurid domes in controlled fluvial settings: A case study in experimental dinosaur taphonomy. Palaios. 28(5), 285-292. https://doi.org/10.2110/palo.2013.p13$003 \mathrm{r}$

Peterson, J.E., Dischler, C., \& Longrich, N.R. (2013). Distributions of cranial pathologies provide evidence for headbutting in dome-headed dinosaurs (Pachycephalosauridae). PLoS One, 8(7), e68620. https://doi.org/10.1371/journal.pone.006 8620 
Peterson, J.E., \& Vittore, C.P. (2012). Cranial pathologies in a specimen of Pachycephalosaurus. PLoS One, 7(4), 236277.

https://doi.org/10.1371/journal.pone.003 6227

Pruden, M.J., Mendonca, S.E., \& Leighton, L.R. (2018). The effects of predation on the preservation of ontogenetically young individuals. Palaeogeogr Palaeoclimatol Palaeoecol. 490, 404-414. https://doi.org/10.1016/j.palaeo.2017.11 .019

Riccomi, G., Fornaciari, G., \& Giuffra, V. (2019). Multiple myeloma in paleopathology: A critical review. Int $\mathrm{J}$ Paleopathol. 24(November 2018), 201-212. https://doi.org/10.1016/j.ijpp.2018.12.0 01

Rigby, J.K.J., Rice, A., \& Currie, P.J. (1987). Dinosaur thermoregulatory Cretaceous/Tertiary survival strategies. Geol Soc Am Abstr with Programs, 19(7), 820.

Robling, A.G., \& Stout, S.D. (1999). Morphology of the drifting osteon. Cells Tissues Organs. 164(4), 192-204. https://doi.org/10.1159/000016659

Schnitzler, C.M. (2015). Childhood cortical porosity is related to microstructural properties of the bone-muscle junction. $\mathrm{J}$ Bone Miner Res. 30(1), 144-155. https://doi.org/10.1002/jbmr.2312

Schott, R.K., \& Evans, D.C. (2012). Squamosal ontogeny and variation in the pachycephalosaurian dinosaur Stegoceras validum Lambe, 1902, from the Dinosaur Park Formation, Alberta. J Vertebr Paleontol, 32(4), 903-913. https://doi.org/10.1080/02724634.2012. 679878

Schott, R.K., \& Evans, D.C. (2016). Cranial variation and systematics of Foraminacephale brevis gen. nov. and the diversity of pachycephalosaurid dinosaurs (Ornithischia: Cerapoda) in the Belly River Group of Alberta, Canada. Zool J Linn Soc., 179(4), 865906. https://doi.org/10.1111/zoj.12465

Schott, R.K., Evans, D.C., Goodwin, M.B., Horner, J.R., Brown, C.M., \& Longrich, N.R. (2011). Cranial ontogeny in Stegoceras validum (Dinosauria: Pachycephalosauria): A quantitative model of pachycephalosaur dome growth and variation. PLoS One, 6(6), e21092.

https://doi.org/10.1371/journal.pone.002 1092

Schott, R.K., Evans, D.C., Williamson, T.E., Carr, T.D., \& Goodwin, M.B. (2009). The anatomy and systematics of Colepiocephale lambei (Dinosauria: Pachycephalosauridae). J Vertebr Paleontol, 29(3), 771-786. https://doi.org/10.1671/039.029.0329

Schultz, M. (2001). Paleohistopathology of bone: A new approach to the study of ancient diseases. Am J Phys Anthropol. 44, 106147. https://doi.org/10.1002/ajpa.10024

Silverman, S. (2006). Diagnostic Imaging. In: Mader DR (Ed.) Reptil Med Surg. (2nd ed). St. Louis: Saunders Elsevier.

Siviero, B.C.T., Rega E., Hayes, W.K., Cooper, A.M., Brand, L.R., \& Chadwick, A.V. (2020). Skeletal trauma with implications for intratail mobility in Edmontosaurus annectens from a monodominant bonbed, Lance Formation (Maastrichtian), Wyoming USA. Palaios. 35, 201-214. https://doi.org/10.2110/palo.2019.079

Skedros, J.G., Sorenson, S.M., \& Jenson, N.H. (2007). Are distributions of secondary osteon variants useful for interpreting load history in mammalian bones? Cells Tissues Organs. 185(4), 285-307. https://doi.org/10.1159/000102176

Skedros, J.G., Su, S.C., \& Bloebaum, R.D. (1997). Biomechanical implications of mineral content and microstructural variations in cortical bone of horse, elk, and sheep calcanei. Anat Rec. 249, 297316. https://doi.org/10.1002/(SICI)10970185(199711)249:3\%3C297::AIDAR1\%3E3.0.CO;2-S

Skinner, M.F., Durpras, T.L., \& Moyà-Solà, S. (1995). Periodicity of linear enamel hypoplasias among Miocene Dryopithecus from Spain. J Paleopathol. 7(3), 195-222.

Snively, E., \& Cox, A. (2008). Structural mechanics of pachycephalosaur crania permitted head-butting behavior. Palaeontol Electron, 11(1), 3A: 17.

Snively, E., \& Theodor, J.M. (2011). Common functional correlates of head-strike behavior in the pachycephalosaur Stegoceras validum (Ornithischia, Dinosauria) and combative artiodactyls. PLoS One. 6(6), e21422. 
https://doi.org/10.1371/journal.pone.002 1422

Sues, H-D., \& Galton, P.M. (1987). Anatomy and classification of the North American Pachycephalosauria (Dinosauria: Ornithischia). Palaeontogr Abteilung A. 198, 1-40.

Sullivan, R.M. (2003). Revision of the dinosaur Stegoceras Lambe (Ornithischia, Pachycephalosauridae). J Vertebr Paleontol, 23(1), 181-207. https://doi.org/10.1671/02724634(2003)23[181:ROTDSL]2.0.CO;2

Sullivan, R.M. (2006). A taxonomic review of the Pachycephalosauridae (Dinosauria: Ornithischia). In: Lucas SG, Sullivan RM, editors. Late Cretac Vertebr form West Inter. Albuquerque: New Mexico Museum of Natural History Bulletin 35; p. 347-365.

Teitelbaum, S.L., Stewart, C.C., \& Kahn, A.J. (1979). Rodent peritoneal macrophages as bone resorbing cells. Calcif Tissue Int. 27(1), 255-261. https://doi.org/10.1007/BF02441194

Thompson, C.E.L., Ball, S., Thompson, T.J.U., \& Gowland, R. (2011). The abrasion of modern and archaeological bones by mobile sediments: The importance of transport modes. J Archaeol Sci. 38(4), 784-793.

http://dx.doi.org/10.1016/j.jas.2010.11.0 01

Uchman, A., Álvaro, J.J. (2000). Non-marine invertebrate trace fossils from the Tertiary Calatayud-Teruel basin, NE Spain. Rev Española Paleontol., 15(2), 203-218.
Wallach, J.D. (1975). The pathogenesis and etiology of ulcerative shell disease in turtles. J Zoo Anim Med. 6(1), 25-28.

Watabe, M., Tsogtbaatar, K., \& Sullivan, R.M. (2011). A new pachycephalosaurid from the Baynchire Formation (CenomanianLate Santonian), Gobi Desert, Mongolia. In: Sullivan RM, Lucas SG, Spielmann JA, editors. Foss Rec 3. Albuquerque: New Mexico Museum of Natural History and Science Bulletin 53; p. 489-497.

Weaver, V., Goodwin, M., \& Horner, J. (2014). Histology of pachycephalosaurid crania reveals evidence of multiple tissue types and variable origin of apical pathologies. In: Maxwell E, Miller-Camp J (Editors. Soc Vertebr Paleontol Novemb 2014 Abstr Pap 74th Annu Meet. Berlin; p. 253.

Williamson, T.E., \& Brusatte, S.L. (2016). Pachycephalosaurs (Dinosauria: Ornithischia) from the Upper Cretaceous (upper Campanian) of New Mexico: A reassessment of Stegoceras novomexicanum. Cretac Res. 62, 29-43. https://doi.org/10.1016/j.cretres.2016.01 .012

Xing, L., Rothschild, B.M., Randolph-Quinney, P.S., Wang, Y., Parkinson, A.H., \& Ran, H. (2018). Possible bite-induced abscess and osteomyelitis in Lufengosaurus (Dinosauria: sauropodomorph) from the Lower Jurassic of the Yimen Basin, China. Sci Rep. 8, 5045. https://doi.org/10.1038/s41598-01823451-x

Publisher's note: Eurasia Academic Publishing Group (EAPG) remains neutral with regard to jurisdictional claims in published maps and institutional affiliations.

Open Access This article is licensed under a Creative Commons Attribution-NoDerivatives 4.0 International (CC BY-ND 4.0) licence, which permits copy and redistribute the material in any medium or format for any purpose, even commercially. The licensor cannot revoke these freedoms as long as you follow the licence terms. Under the following terms you must give appropriate credit, provide a link to the license, and indicate if changes were made. You may do so in any reasonable manner, but not in any way that suggests the licensor endorsed you or your use. If you remix, transform, or build upon the material, you may not distribute the modified material.

To view a copy of this license, visit https://creativecommons.org/licenses/by-nd/4.0/. 